العلاقة بين الفقر والنمو الإقتصادى

بالتطبيق على الحالة المصرية

خلال الفترة (2000/1999- 2018/2017)

بحث مقدم من الباحثة

د/ إيمان محمد عبد اللطيف مصطفى

مدرس بقسم الاقتصاد

كلية الإدارة والاقتصاد ونظم المعلومات

جامعة مصر للعلوم والتكنولوجيا

ملخص الدراسة:

يمثل الفقر عقبة أساسية فى سبيل تحقيق التتمية المستدامة ورفع معدلات النمو

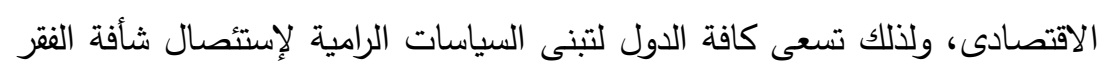
والنهوض بمستوى معيشة المواطنين، و من هنا تبحث الدراسة فى ثلاث إثكاليات هى:

* رغم تزايد الإستثمارات الموجهة لمحافظات الصعيد إلا أن الفجوة الدخلية مازالت قائمة بينها و بين المحافظات الأخرى. رغالد الإنمات

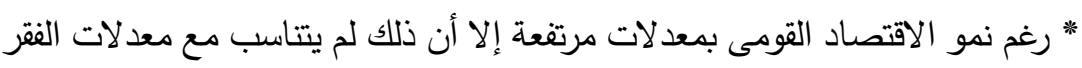

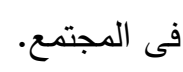
* رغم تزايد إنفاق الدولة و المؤسسات غير الهادفة للربح على مشاريع الحماية

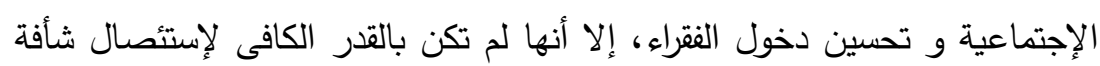


وتمثلت المنهجية المتبعة فى الدراسة فى منهجيتى الإستتباط و التحليل، ويتناول البحث خمسة أقسام، يتعرض اولها إلى الإطار المرجعى لدراسات الفقر ، وثانيها إلى مشكلة الفقر في مصر من حيث الحجم والأبعاد، أما القسم الثالث فيتتاول

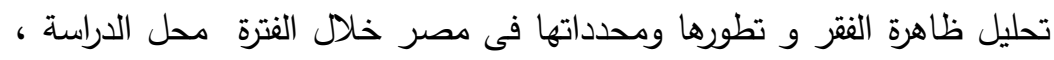
ويتتاول القسم الرابع تحليل وتقويم السياسات والاجراءات المطبقة لمواجهة مشكلة الفقر في مصر، وتعرض الدراسة فى القسم الخامس لأهم الإستخلاصات

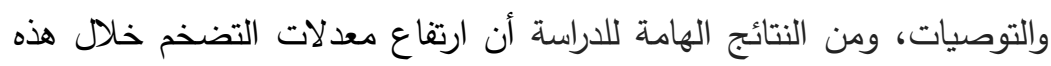

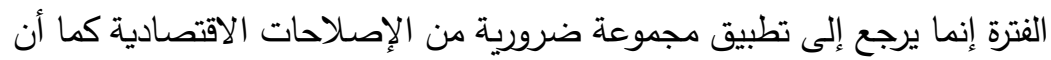

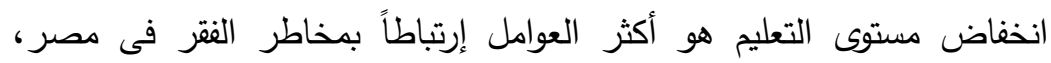

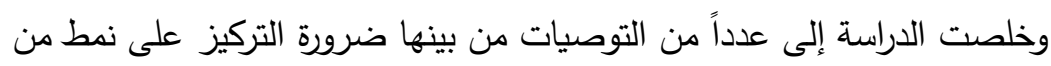
النمو الإحتوائى يضمن خلق فرص عمل أكثر و أفضل.

\section{كلمات مفتاحية:}

الفقر - النمو الاقتصادى- الفقر المدقع - الفقر المطلق - شأفة الفقر - الفقر متعدد الأبعاد - معدل التضخم - البطالة - الفقر النسبى - النمو الداعم للفقراء. مقدمة: - مقاد

يُُثل الفقر عقبة أساسية فى سبيل تحقيق التتمية المستدامة ورفع معدلات النمو

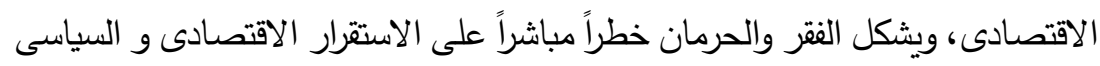

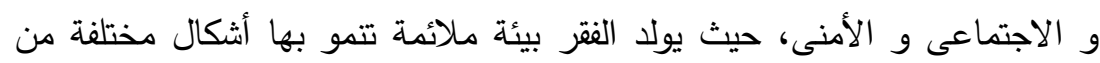
الانحراف و التطرف و الممارسات غير السوية. ولذلك، تسعى كافة الدول لتبنى

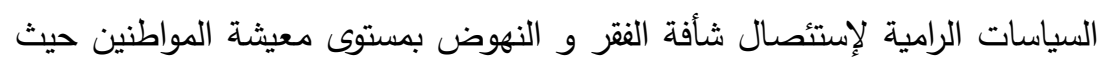

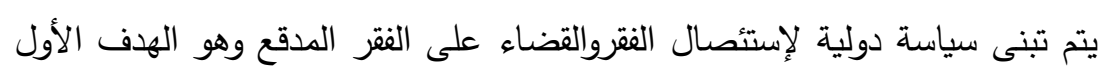

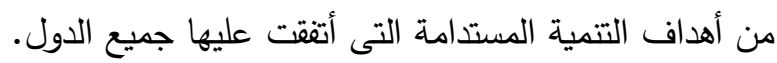


إثكاليات الاراسة:--

تبحث الدراسة فى ثلاث إثكاليات مطروحة لمشكلة الفقر بهدف الوقوف على

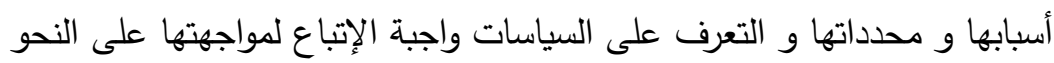
الآتى: * رغم نمو الاقتصاد القومى بمعدلات مرتفعة إلا أن ذلك لم يتناسب مع معدلات الفقر

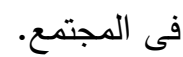
* رغم تزايد إنفاق الدولة و المؤسسات غير الهادفة للربح على مشاريع الحماية الإجتماعية و تحسين دخول الفقراء، إلا أنها لم تكن بالقدر الكافى لإستئصسال شأفة الفقر .

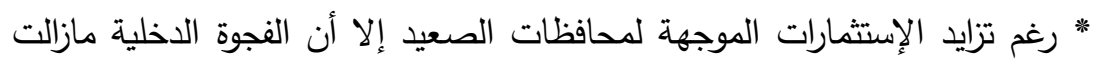
قائمة بينها و بين المحافظات الأخرى. رؤر الأنمارات أهداف الاراسة : تتمثل أهداف الدراسة فيى الآتىى: 1 - التعرف علي حجم مشكلة الفقر في مصر وأبعادها المختلفة

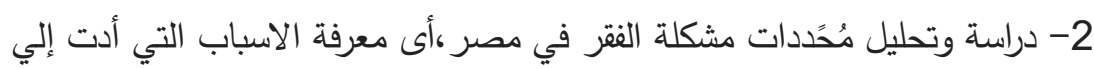

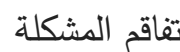
r- عرض وتقويم السياسات والاجرءات المطبقة للتخفيف من حِّدة مشكلة الفقر وتوصيات الدراسة في هذا الثأن.

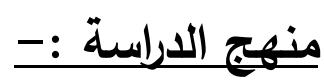

تمثلت المنهجية المتبعة فى الدراسة فى منهجيتى الإستتباطو التحليل، حيث تستعرض

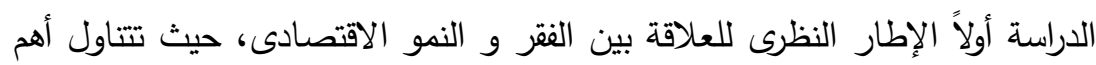

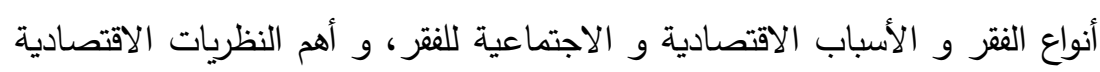

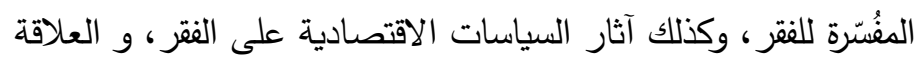




\begin{tabular}{|c|c|}
\hline تاريخ قبول النشر 2020/11/1 & الفقر والنمو الاقتصادى \\
\hline
\end{tabular}

بين النمو الإقتصادى و الفقر فى إطار نظرية النمو المحابى أو الداعم للفقراء، والعلاقة بين النمو الاقتصادى و العدالة فى توزيع الدخل.

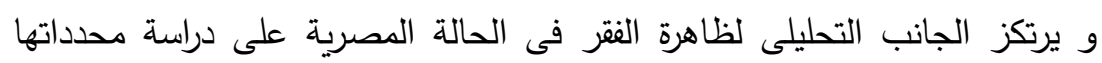
و تحليل وتقويم السياسات والاجراءات المطبقة لمواجهة الظاهرة. خطة البحث:- وليم ينقسم البحث إلى خمسة أقسام على النحو التالى: القسم الأول: الإطار المرجعى لدراسات الفقر(الأدبيات النظرية و الدراسات التطبيقية) القسم الثانى: مشكلة الفقر في مصر : الحجم والأبعاد القسم الثالث: تحليل ظاهرة الفقر و تطورها ومحدداتها فى مصر خلال الفترة (2018 /2017 -2000/1999) القسم الرابع: تحليل وتقويم السياسات والاجراءات المطبقة لمواجهة مشكلة الفقر في مصر القسم الخامس: النتائج و توصيات الدراسة

القسم الأول : الإطار المرجعى لاراسات الفقر

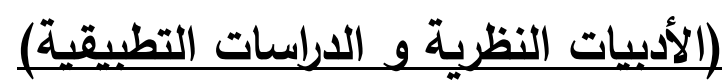

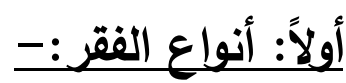

يوجد أنواع متعددة للفقر على النحو الآتى 1 :

1-Tikhomova, N.2015, "The Structural Preconditions and Basic Types of

.Poverty in Russia", Sociological Research, Vol.54, Issue. 1 


\section{1 - الفقر النقدى:-}

وهو ذلك النوع الذى يكون فيه الفقير غير قادر على تحمل النفقات و يعبر عنه "

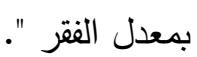

$$
\text { 2- الفقر المطلق:- }
$$

وهو ذلك النوع الذى لايستطيع فيه الفقير بواسطة دخله الوصول إلى إثباع حاجاته

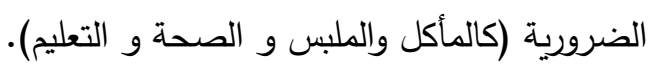

$$
\text { 3- الفقر النسبح:- }
$$

وهو ذلك النوع الذى يبرز الفروق فى مستويات الموارد النسبية وعدم المساواة فى توزيع تلك الموارد فى المجتمع، أى يمكن وصفه بأنه إفتقار الفرد أو الجماعة إلى الموارد مقارنة بأفراد المجتمع الآخرين. 4-الفقر المدقع:-_وهو ذلك النوع الذى يكون فيه الفرد غير قادر على الوصول إلى إثباع حاجاته الغذائية بواسطة دخله. 5- الفقر متعدد الأبعاد:يشمل مؤشر الفقر متعدد الأبعاد عناصر غير مادية كتوافر الإحتياجات الأساسية من الخدمات العامة (مثل الصحة و التعليم و المسكن المناسب) ثانياً: الأسباب الاقتصادية و الاجتماعية للفقر 3. 1- الأسباب الاقتصادية:تتمثل الأسباب الاقتصادية للفقر فى الآتى: الاسيب: أ- تدنى مستويات الدخول و الموارد اللازمة للحصول على الضئه الضروريات الأساسية كالغذاء، المأوى، الملبس، و انخفاض مستويات الصحة والتعليم.

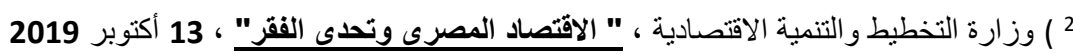

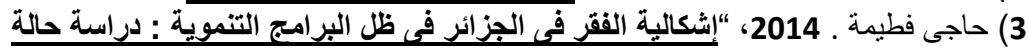

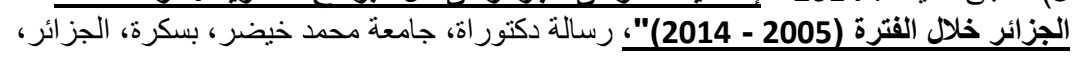

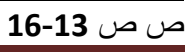




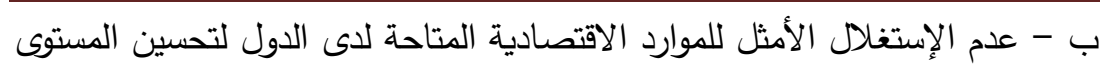
الاقتصادى و الاجتماعى، ويصبح المجتمع إستهلاكى وغير منتج.

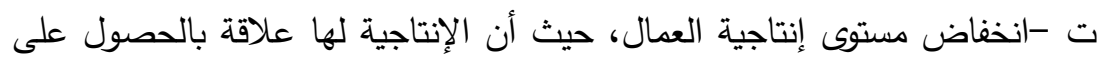
التعليم و الخدمات الصحية والإنتمان.

ث-ارتفاع معدلات البطالة و الدين الخارجى و الأزمات المالية و التى تسبيت فى في الكثير من المشاكل للفقراء

\section{2- الأسباب الاجتماعية:-}

تتمثل الأسباب الاجتماعية للفتر فى الآتى:

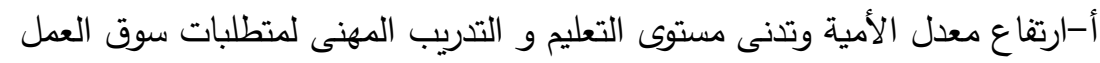

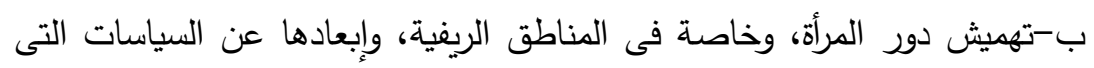

تحد من الفقر .

ت-التفاوت الصارخ فى توزيعات الثروة و الدخول و الذى يؤدى إلى إقصاء شرائح

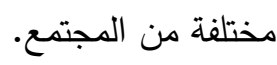
ث-إنتشار الفساد والبيروقراطية، مما يلحق الضرر بتوزيع الإنفاق العام ويعرقل النمو ج-ضعف قدرة المؤسسات الرسمية وغير الرسمية فى مكافحة الفقر .

\section{ثالثاً: الفقر فى النظرية الاقتصادية:-}

تعددت رؤى وتوجهات المدارس الاقتصادية لظاهرة الفقر و تطورها عبر العصور منذ

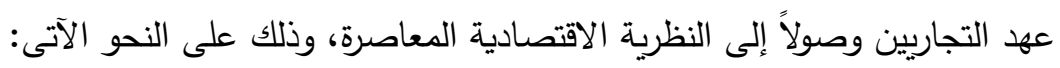
1- الفقر فيى الفكر الاقتصادى التجارى:--

عرفت مرحلة التجاريين بروز الطبقة الوسطى (التجار ) على حساب طبقة النبلاء،

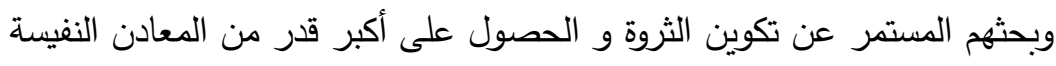


لتعزيز مكانة الدولة، إذ أعتبروا تحقيق الثروة مرادفا للغنى و الرفاهية و نقيض لحالة

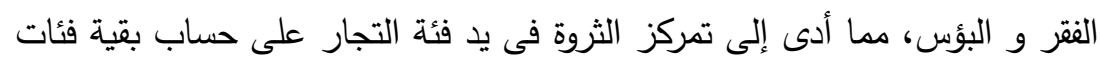
المجتمع

\section{2- الفقر فحى المذهب الطيعى:-}

وفقاً لمذهب الطبيعيين، فإن الفقر يمثل إنحرافاً عن النظام الطبيعى، حيث يتضمن

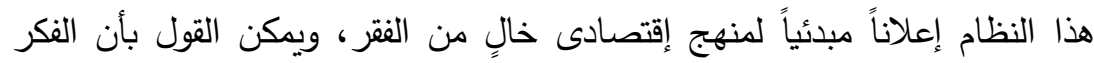
الطبيعى قد وقف عاجزاً عن تقديم تفسيراً واضحاً لظاهرة الفقر فى ظل نموذج اقتصاد

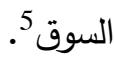

\section{3- الفقر في الفكر الاقتصادى الكلاسيكى:-}

لم يتاول الكلاسيك قضية الفقر بالتحليل بشكل مباشر ، وانما تم تناولها بشكل عرضى من خلال مناقشة قضايا العمل والأجر و توزيع عوائد الإنتاج وتحقيق العدالة الاجتماعية، وتجست رؤية الكلاسيك فى تحليل ظاهرة الفقر فى الآتى:

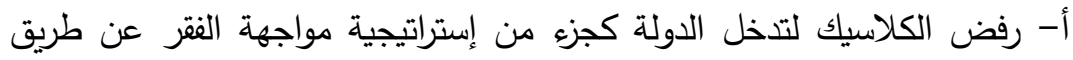

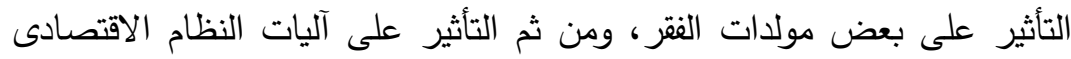

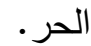

ب - اعتبار الكلاسيك ظاهرة الفقر بأنها خارج النظام الاقتصادى، وأنها وليدة ظروف شخصية ولاتمس إلا فئات من المجتمع، وهى الفئات التى لاتملك الحد المقبول من

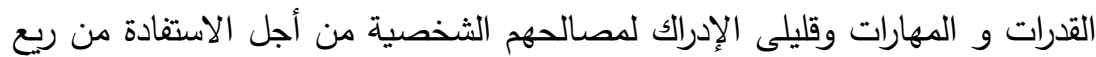

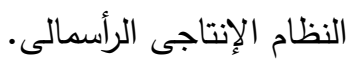

4) عمر بوزيد أمحمد . 2011 / 2012 ، " نمذجة ظاهرة الفقر في الجزائر "33 ،

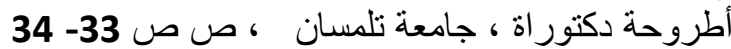

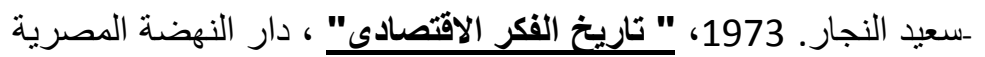
5) Brady, D. 2019, "Theories of the Causes of Poverty", Annual Review of Sociology, Vol.45, pp : 155- 156. 
ت-اعتبار الكلاسيك الأوائل، أن الفقر متغير أساسى فى عملية النمو حيث أن الأجور

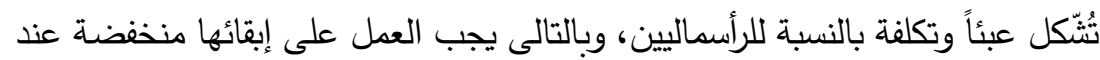

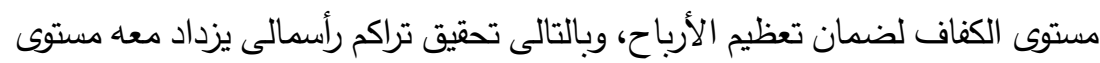

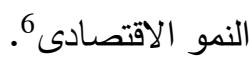

\section{4-الفقر في الفكر الاقتصادى النيوكلاسيكى:-}

إنصب الاهتمام فى الفكر التقليدى الحديث على الطريقة التى يعمل بها الاقتصاد

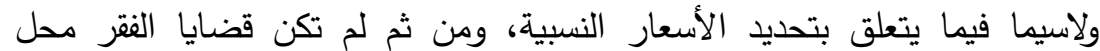
الإهتمامجام

وبشكل عام، فإن مفهوم الفقروفقا للنظرية الكلاسيكية و النيوكلاسيكية يرتبط ارتباطاً

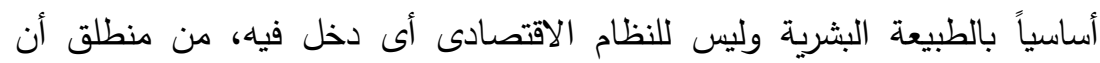

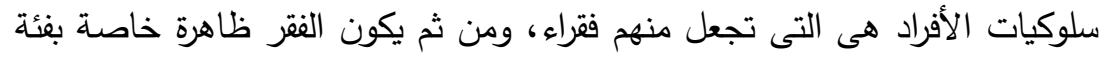
غير المؤهلين للاندماج فى الحياة الاجتماعية. 5-الفقر فى الفكر الاقتصادى الإثتراكى:-

وفقا للإشتراكية الماركسية، فإن عملية خلق الثروة تصاحبها دائما خلق للمزيد من الفقر و الإقصاء فى المجتمع وذلك من خلال الاستغلال و القهر و البطالة. وقد قدّم الفكر الإثتراكى رؤيته لاقتصاد بلا فقر من خلال تأكيده على الملكية الجماعية

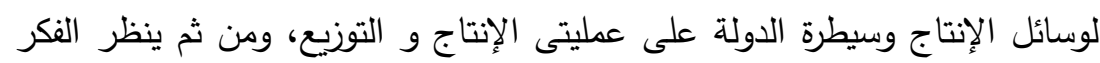

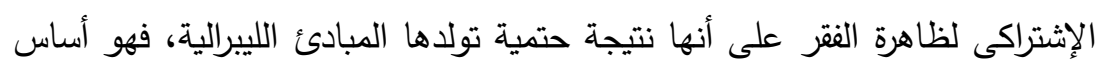

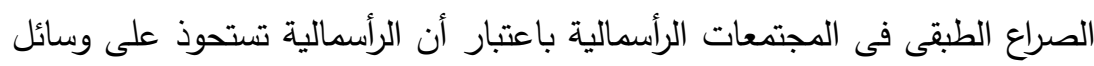
الإنتاج و تستغل الطبقة العاملة لديها 8.

6) نورى عبد الرسول الخاقانى، طالب حسين فارس الكريطى .2015، “الفكر الإقتصادى حول الفقر

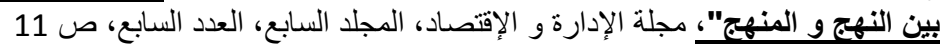
7) Davis, E and Sanchez, M. 2014, "AReview of the Economic Theories of Poverty", No.435,p20

8) حاجى فطيمة، “مرجع سبق ذكره"؛ ص 16. 
أعتبرت هذه النظرية الفتر بأنه لايعدو عن كونه مظهراً من مظاهر البطالة، ففى

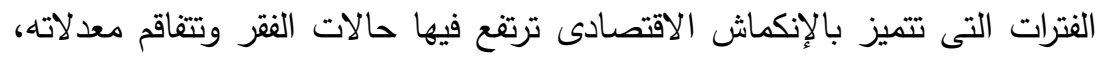

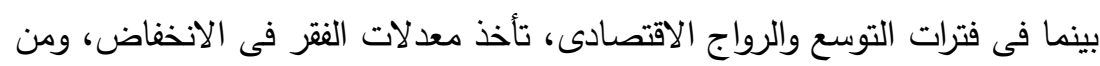

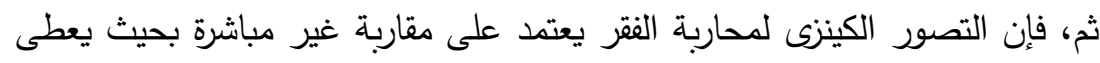

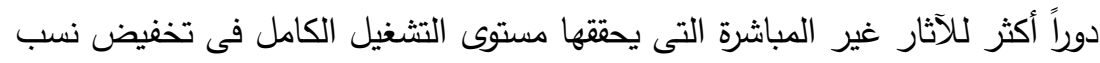
الفقروهو بذلك لايعطى أهمية للأسباب المباشرة فى تغير حالة الفقر من خلال تمويل

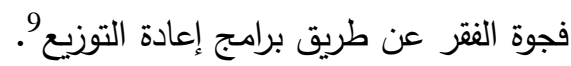
7-نظرية الرفاهية فى الفقر: تقوم هذه النظرية على القياس المادى للرفاهية وذلك بإستخدام الدخل أو الإنفاق الإستهلاكى للتعبير عن مستوى الرفاهية، وذلك بإعتبار الدخل هو معيار للفقر ، فنظرية

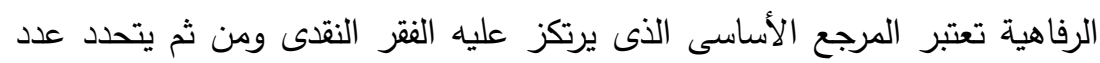

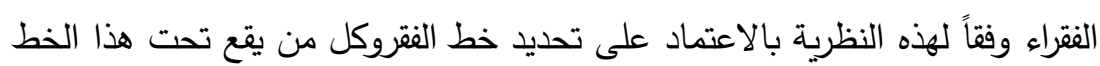
يعتبر فقيرًا

\section{8-نظربـة الحلقة المفرغة:-}

تفترض هذه النظرية استمرار الفقر من خلال تعزيز حلقات مفرغة فى جانبى الطلب والعرض، و أن هناك مجموعة من العوامل التى تتفاعل مع بعضها بطريقة دائرية،

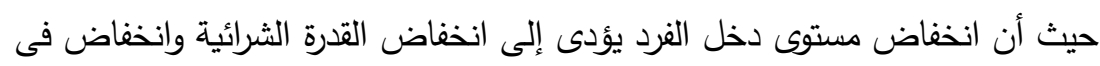
الإستثمار يؤدى إلى تتاقص الإنتاجية وبالتالى انخفاض مستوى الدخل هذا من جانب إنغاض

9) Pressman, S. 1991, "Keynes and Antipoverty Policy", Taylor and Francis, Vol.49, No.3.

10) Tinbege, J, "On the Measurement of Welfare", Journal of Economics, Vol. 50, P7.

- Sinn, H. W and Scand, J.1995, "ATheory of The Welfare State of Economics", University of Munich,Germany, Vol. 97, No.4 . 
الطلب، أما من جانب العرض، فإن انخفاض الدخل يؤدى إلى تراجع معدل الإدخار

و نقص رأس المال وبالتالى استمرار حالة الفقر 11.

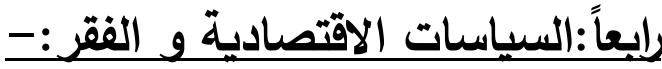

تُؤثر السياسات الاقتصادية على الفقر حيث يرتبط ذلك الآخير بالناتج المحلى، الإستهلاك، الدخل، التوظف، المستوى العام للأسعار ، السياسة النقدية، و السياسة

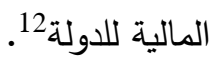
وتتمثل هذه السياسات الاقتصادية فى الآتى: 1-السياسة المالية:-

تكمن أهمية السياسة المالية فى دورها فى الحد من الفقر من خلال أدواتها كالإنفاق و الضرائب وأثرهما على النمو الإقتصادى، فمن ناحية، يؤثر الإنفاق الحكومى على لهى

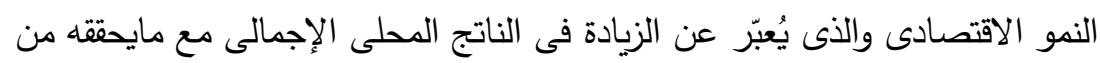

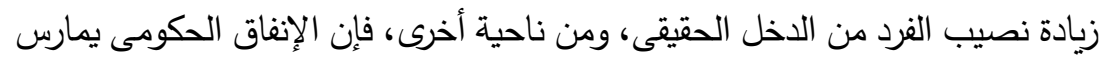

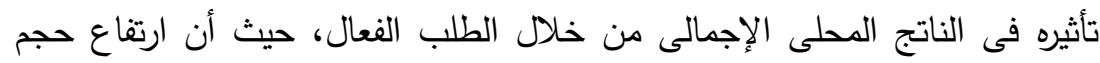
الطلب الفعال بثقيه الإستثمارى و الإستهلاكى يرفع مستوى التثغيل، مما يؤدى إلى الى

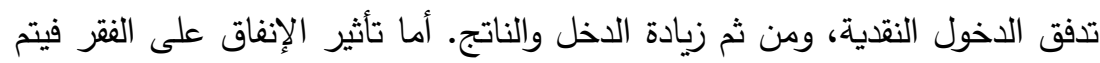

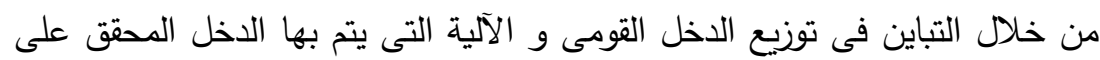
مختلف الفئات الاجتماعية 13.

10 ) أشرف يونس عبد الكريم الخطيب ـ 2016، “العلاقة بين الفقر و النمو الإقتصادى فى فلسطين

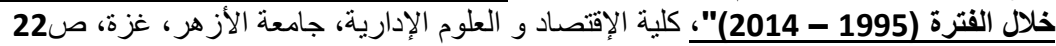
12) Mohammed, T. 2018, "Simulation of the Impact of Economic Policies on Poverty and Inequality : GEM In Micro - Simulation for the ALGERIAN Economy", International Review of Applied Economics, Vol. 32,No.3. 
وكذلك تمارس الضرائب دوراً فعالاً فى زيادة الطلب الكلى، فقى حالة قيام الدولة بتخفيض نسبة الضريبة على الدخل المنخفض، فإنها بذلك تزيد من الطلب الإستهلاكى

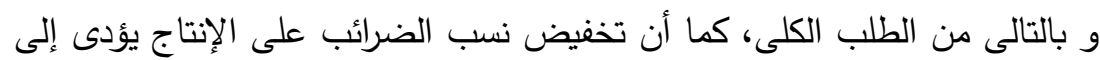

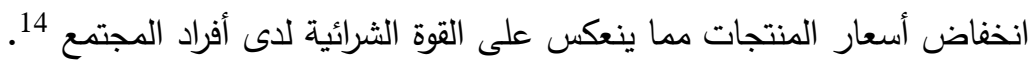

\section{2-التمويل الأصغر:-}

وهو عبارة عن تقديم وتوفير الخدمات المالية للفقراء القادين على تتظيم المشروعات كالإقراض والإيداع و الإدخارو التى تتكيف مع إحتياجاتهم، حيث أصبح التمويل

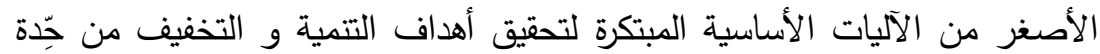
مشكلة الفقر 15. 3- التضخم:يتحقق التأثير المباشر للتضخم عل دخل الأسر المعيشية من خلال الأثر فى الأجور

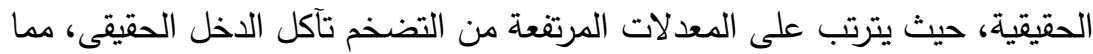
يؤدى إلى تفاقم حِدة الفقر ، حيث أن الفقراء لايملكون من الوسائل والإمكانيات ومنها

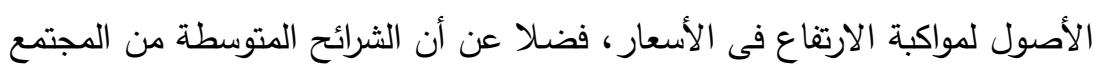

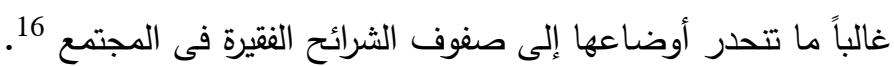

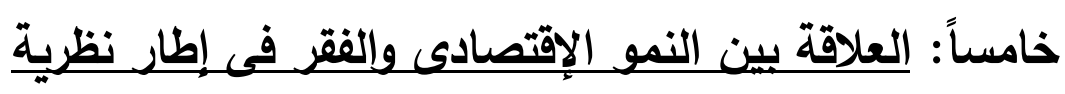
النمو المحابى أو الداعم للفقراء: تتدرج مقاربة النمو الداعم للفقراء Pro- Poor Growth ضمن العلاقة الإجمالية التى تربط كل من النمو و الفقر و التفاوت فى توزيع الدخل، فهى مقاربة حديثة نسبياً قد

14) ليلى بن سنوسى، مسعودة جديد. 2011، “"الضر ائب و آثارها على التنمية"، معهد العلوم

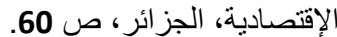
15) موسى منصور. 2012، "دور التمويل الأصغر فى محاربة الفقر في المناطق الريفية"، كلية

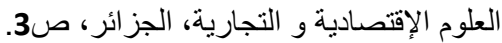
16) صندوق النقد الدولى. 2001، “التنمية المالية و الحد من الفقر"؛ ورقة عمل صادرة من

صندوق النقد الدولى، ص16. 


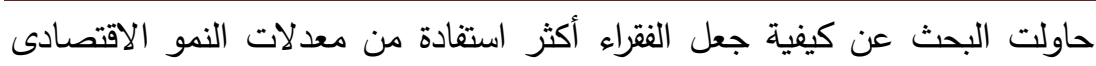

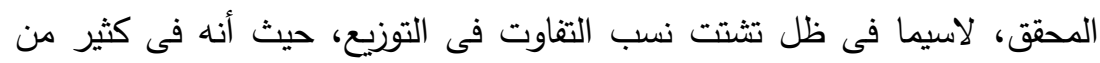
الحالات لايكون هنالك تخفيض ملحوظ فى معدلات الفقر بالرغم من تحقيق معدلات لهات

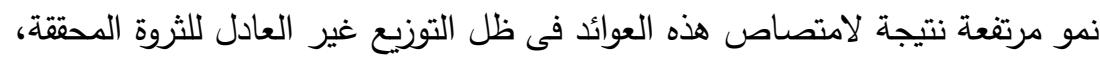
حيث تهدف هذه المقاربة إلى البحث عن الآليات لجعل النمو مفيداً للفقراء 17.

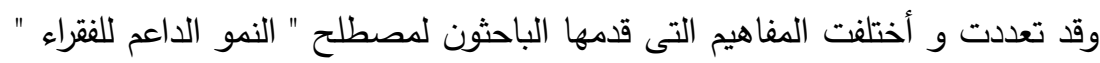

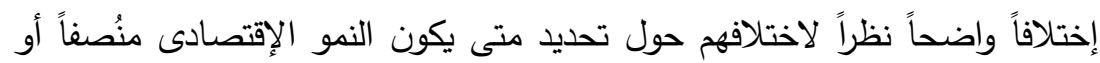

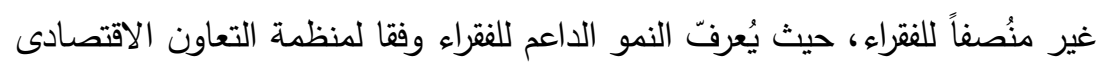
و التمية (OECD) عام 2001 و الأمم المتحدة عام 2002 بأنه كل نمو يخفض أنصاء بثكل معنوى نسبة الفقر، وهو تعريف بسيط قد أعتمد على وجود علاقة إيجابية بين

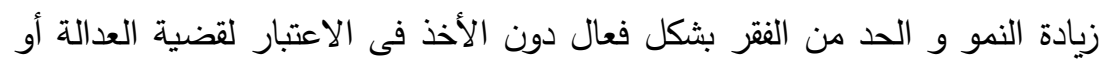
التقاوت فى توزيع الدخل 18. وينبغى التمييز عند الحديث عن النمو المفقر بين مقاربتين تم تتاولهما من جانب الأدبيات النظرية على النحو الآتى:

\section{1-المقاربة المطلقة للنمو الأعم للفقراء: :-}

يعرف النمو الداعم للفقراء فى شكله المطلق بأنه ذلك النمو الذى يقلل من الفقر ، و

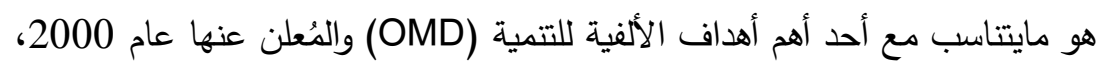
وهو تقليص عدد الفقراء إلى النصف بحلول عام 2015. ويلاحظ أن هذا التعريف يأخذ فى الاعتبار دخول الفقراء فقط كمؤشر على وجود نمو داعم لهم دون مراعاة

17) Aliona, J. 2017,"Pro-Poor Growth : Definition, Measurement and Policy Issues".

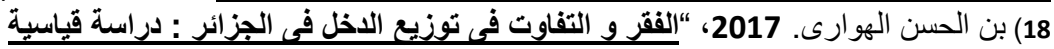

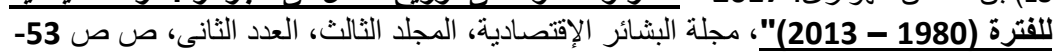


التغيرات فى توزيع الدخل وذلك مهما كانت نسبة ارتفاع دخل الفقراء مقارنة مع ارتفاع دخل غير الفقراء 19.

\section{2-المقاربة النسبية للنمو الاعمب للفقراء: --}

يكون النمو داعماً للفقراء وفقاً لهذه المقاربة إذا كان معدل نمو دخل الفقراء أكبر منه ئه

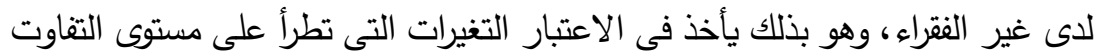

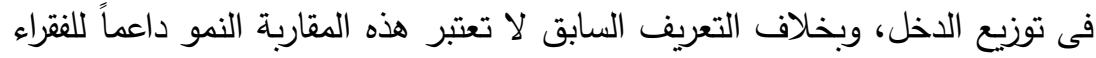

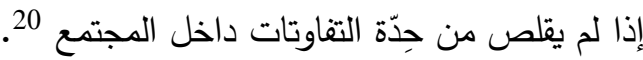

\section{سادساً: العلاقة بين النمو الاقتصادى و العدالة في توزيع}

تختلف العلاقة بين النمو الإقتصادى و العدالة فى توزيع الدخل الناتج عن هذا النمو، حيث يرى البعض أن التفاوت فى توزيع الدخل يعتبر مُحفزاً للنمو الإقتصادى نظراً

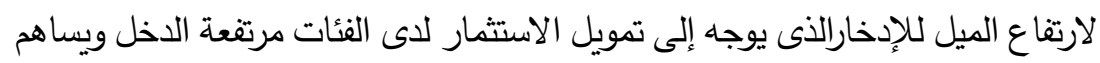
بثكل أساسى فى تحقيق زيادة فى النمو الاقتصادى، وهذا ما ذهب إليه الكلاسيك ،بينما

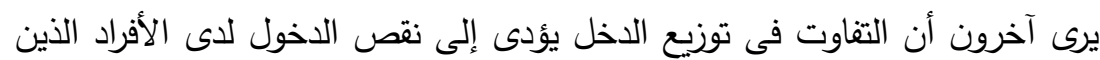

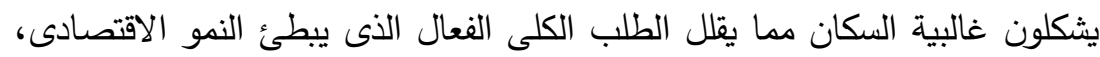

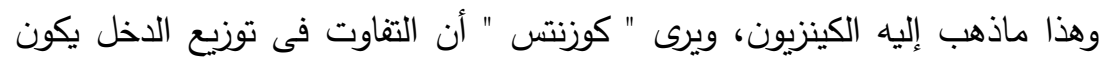

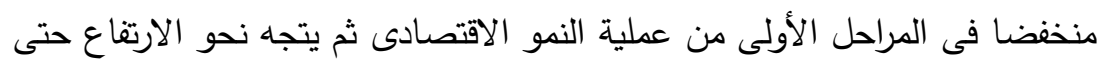
يصل إلى أعلى المعدلات، ثم يتجه إلى الاستقرار ، ثم الانخفاض في الإلى المراحل المتقّدمة

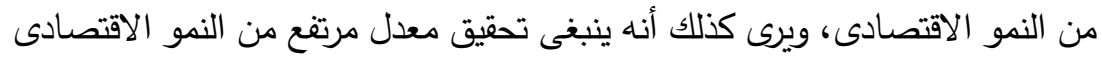

19) Ahlenius, H.2011, "Pro - Poor Growth : Absolute and Relative Definition". 20 )Verme,P.2010,"AStructural Analysis of Growth and Poverty in the Short Run",Journal of Developing Areas, Vol.43, No. 2, pp: 19-23. 
قبل إعادة توزيع الدخل لصالح الفئات محدودة الدخل وذلك بعكس البدء بالتوزيع للاخل ئل

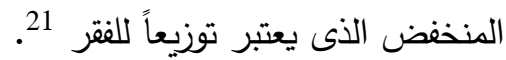

وعلى ذلك يرى بعض الاقتصاديين أن معدلات النمو الإقتصادى المرتفعة قد تساهم

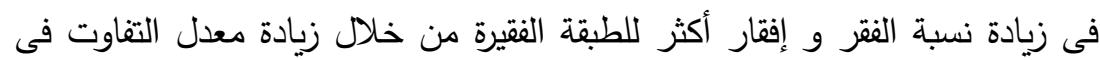

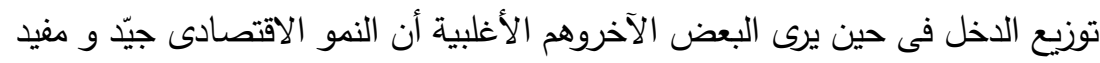

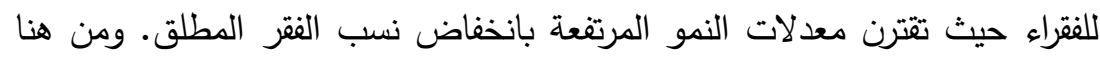
يمكن القول بأن علاقة الفقر بالنمو الإقتصادى قد تكون بإهمال قضية توزيع الدخل و

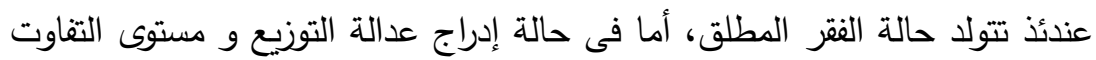

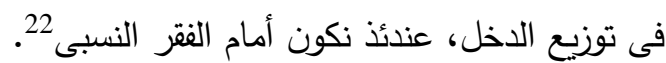

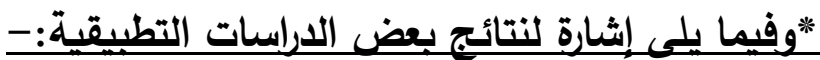 1-هناء خير الدين، هبة الليث، 2006، "العلاقة بين النمو الاقتصادى و توزيع الاخل و الحد من الفقر فى مصر ":} هدفت الدراسة إلى تفسير النمو الإقتصادى المشاهد فى مصر من خلال ربطه بزيادة معدلات الفقر خلال الفترة (1990- 2005) وذلك اعتمادا على بيانات سلاسل زمنية وبيانات مقطعية عن الناتج المحلى، التشغيل الكلى و القطاعى، ورصيد رأس المال، إضافة إلى المؤشرات الخاصة بالفقر و توزيع الدخل. وخُلصت الدراسة إلى أن النمو الاقتصادى فى مصر يعتمد بثكل أساسى على كثافة

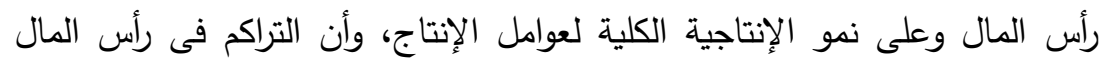

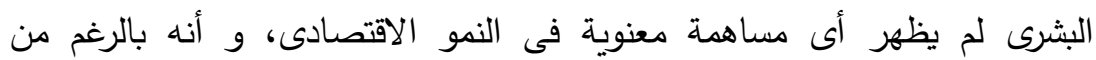

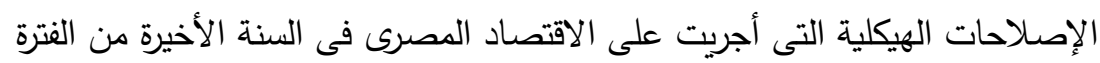

21 زينب السيد. 2015، "عدالة توزيع الاخل و النمو الإقتصادى : الحالة المصرية نموذجاً"؛

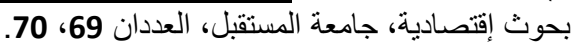
22) Todaro,M and Smith,S, 2015." Poverty; Inequality, and

Development",New York and George Washington University, P226. 


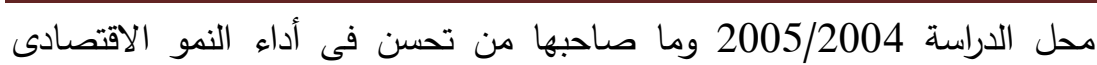
المصرى إلا أن ذلك لم يؤدى إلى تراجع معنوى فى معدل الفقر فى مصر .

2-Angelique G, Nindi,Nicholas, $M$ and Odhiambo , 2015, "Poverty and Economic Growth in Swaziland: An Empirical Investigation":

هدفت الدراسة إلى اختبار العلاقة غير المنتظمة بين انخفاض الفقر و النمو الاقتصادى

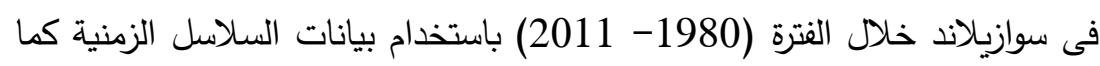
تم استخدام بعض الاختبارات الإحصائية واستخدام اختبار ديكى فولر لهذا الهاف.

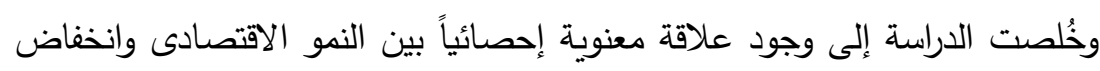

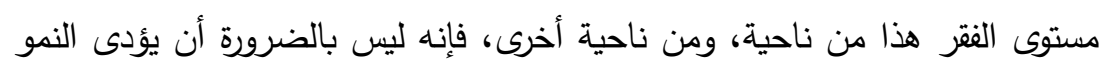

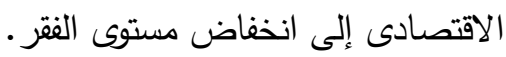

3- Lee,N and Sissons, P. 2016, "Inclusive Growth?, The Relationship Between Economic Growth and Poverty in British Cities ":

هدفت الدراسة إلى دراسة وتحليل العلاقة بين النمو الاقتصادى و الفقر فى المدن

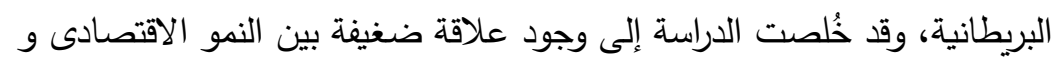

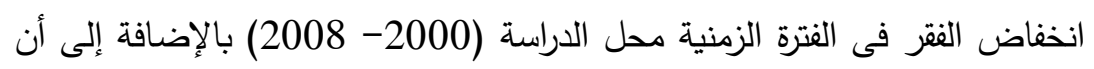
هناك تزامناً بين النمو الاقتصادى ونمو الأجور • 4-أشرف يونس عبد الكربم الخطب،، 2016، "العلاقة بين الفقر و النمو الاقتصادى في فلسطين ":

هدفت هذه الدراسة إلى تحليل العلاقة بين الفقر و النمو الاقتصادى فى فلسطين فى العى الفترة (1995- 2014)، وقد تم استخدام بيانات سلاسل زمنية لدراسة العلاقة بينهما،

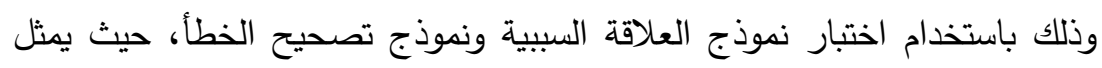
معدل الفقر المتغير التابع، وتمثل المتغيرات (الإنفاق الحكومى - متوسط نصيب الفئ الفرد 


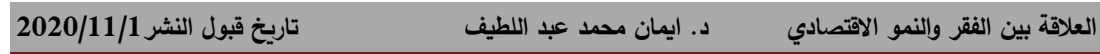

من الناتج المحلى الإجمالى - المساعدات الخارجية - الأوضاع السياسية) متغيرات مستقلة فى النموذج القياسى.

وخُلصت الدراسة إلى وجود علاقة سببية من النمو الاقتصادى إلى الفقر ، أى أنها

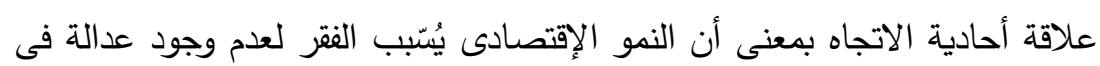

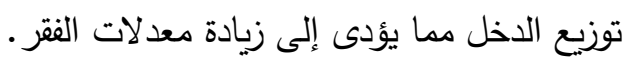

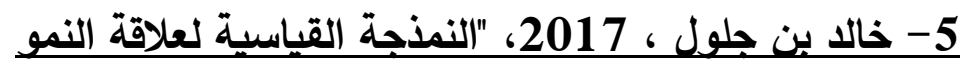
الإقتصادى بمعدلات الفقر فى الجزائر للفترة (1985 - 2015)": هدفت هذه الدراسة إلى تحديد شكل العلاقة و التأثير الذى يمكن أن تمارسه معدلات النمو الاقتصادى فى الجزائر على تخفيض معدلات الفقر و تحسين أوضاع التهل الفقراء. ولتحقيق هذا الهدف، تم تصميم نموذج قياسى للعلاقة بين المتغيرين السابقين خلال الفترة (1985- 2015). وخُلصت الدراسة إلى وجود علاقة وتأثير للنمو الاقتصادى على معدلات الفقر غير (كلى

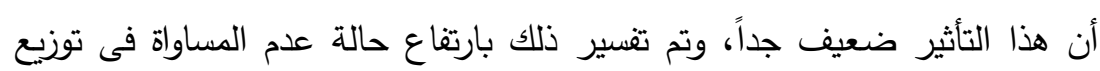

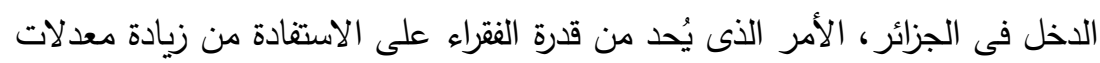

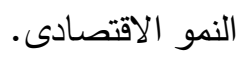

6-بوحزام سيد أحمد، 2018/2017، "النمو المحابى للفقراء فيى الجزائر : دراسة قياسية للفترة (1970- 2016)" هدفت الدراسة إلى البحث عن علاقة النمو الاقتصادى فى الجزائر بالفقر خلال الفترة (1970- 2016) فى محاولة للبحث عن مدى محاباة النمو الاقتصادى فى الجزائر للفقر من خلال استخدام مقاربة ARDL لدراسة النموذج القياسى الذى تضمن المتغيرات:الفقر كمتغير تابع مقاساً بالإنفاق الاستهلاكى الفردى، وكل من معدل نمو

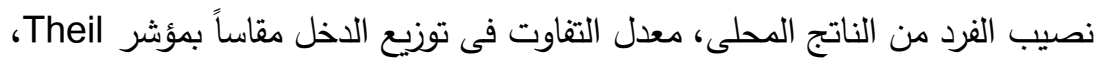
ومؤشر التضخم كمتغيرات مستقلة. 
وخُلصت الدراسة إلى أن النمو الاقتصادى فى الجزائر كان مُحابياً وداعماً للفتراء خلال معظم فترات الدراسة ولاسيما تلك الفترات التى شهدت توسعاً ورخاءً اقتصادياً.

7-Breunig, $R$ and Majeed, $O$.2020, "Inequality, Poverty and Economic Growth",International Economics, Vol.161.

هدفت الدراسة إلى بحث أثر عدم العدالة أو عدم المساواة فى توزيع الدخل على النمو

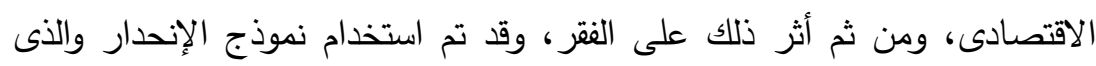

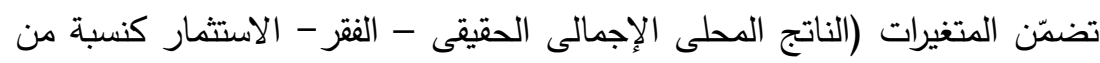

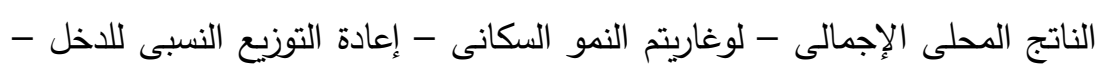

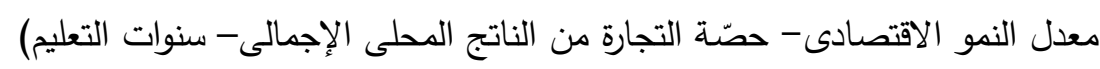

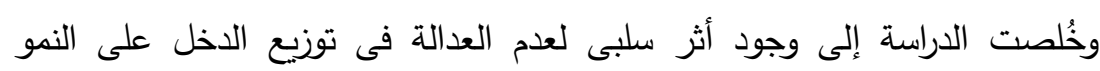

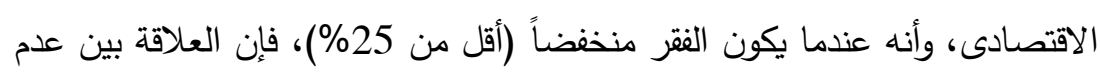
المساواة فى توزيع الدخل والنمو الاقتصادى تكون غير معنوية إحصائياً. 


\section{مشكلة الفقر في مصر : الحجم والأبعاد}

بإستقراء مؤشرات الفقر فى مصر و الصادرة عن الجهاز المركزى للتعبئة العامة و الإحصاء يتضح مايلى:- بإستعراه مؤشرات

* نحو 31 مليون مصرى (أى أكثر من 7.5 مليون أسرة) كانوا تحت خط الفقر عام .2018/2017

* لايزال ثُلثُا الفقراء فى مصر يقطنون فى الريف، و لاتزال أعلى نسبة للفقر من نصيب ريف الصعيد بنحو 52\% ليمثلون بذلك نحو 40\% من إجمالى الفقراء بينما يُمثل سكانه نحو 25\% فقط من إجمالى سكان الجمهورية. * يحتاج كل فرد فقير إلى نحو 150 جنيه مصرى شهرياً فى المتوسط (بأسعار عام

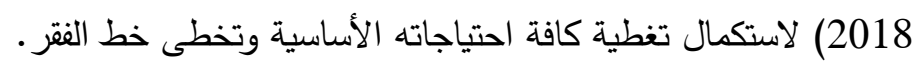
* شهدت معدلات الفقر تصاعداً مطرداً خلا الفترة (1999/ 2000-2017/

2018) شكل رقم (1)

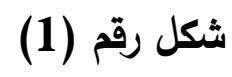

تطور نسبة الفقر فى مصر خلال الفترة (2000/1999- 2018/2017)

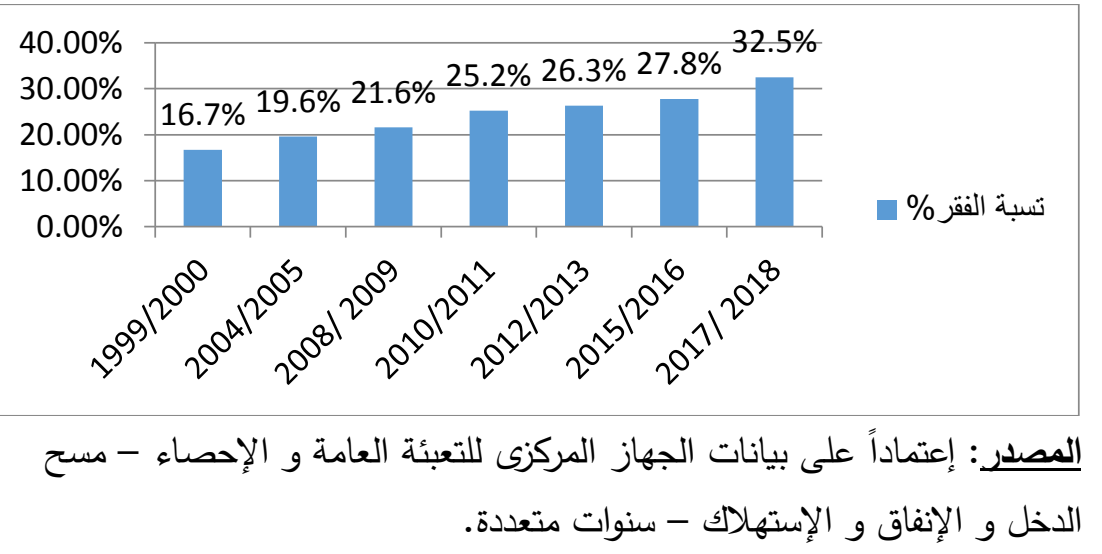


• يوجد تفاوت كبير فى معدلات الفتر بين محافظات الجمهورية، مع ارتفاعها بشكل

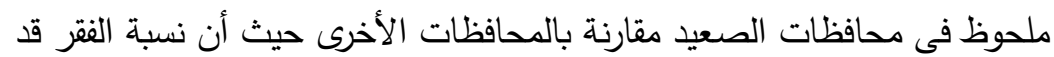

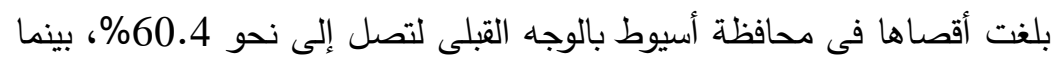
بلغت أدناها فى محافظة بورسعيد بالوجه البحرى لتصل إلى نحو 1 9.1\%، كما يتضح أن نسبة الفقرمتقاربة فى كل من محافظتى جنوب سيناء و دمياط و البالغة نحو 17.9\%، 17.7\% على الترتيب، وكذلك الحال بالنسبة لمحافظتى الفيوم و المنوفية، حيث بلغت تلك النسبة نحو 25.7\%

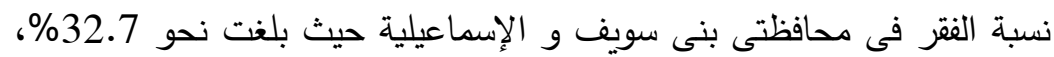
32.4 على الترتيب (شكل رقم2) .

شكل رقم (2) نسبة الفقراء فى محافظات مصر طبقاً لتعداد عام $2018 / 2017$

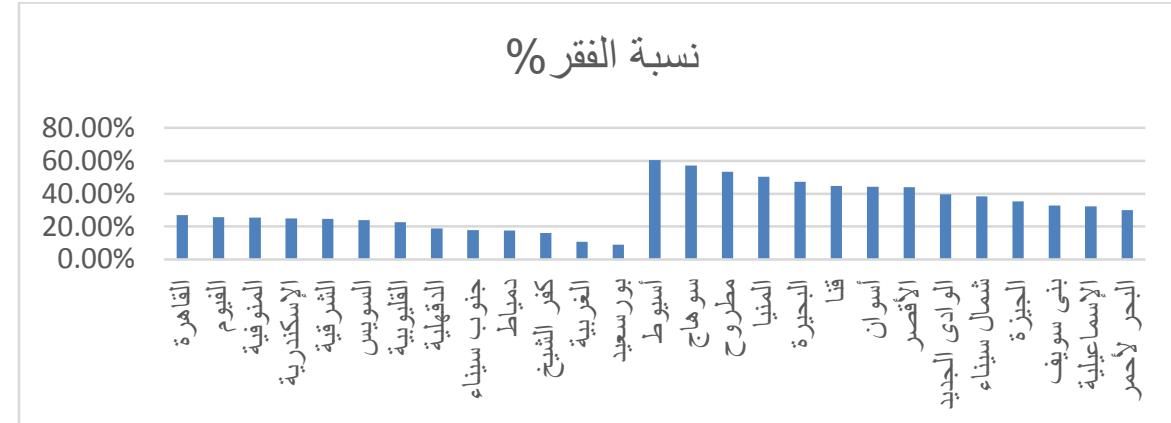

المصدر: إعتماداً على بيانات الجهاز المركزى للتعبئة العامة و الإحصاء، مسح الاخل و الإنفاق و الإستهلاك، سنوات متعددة. * التصاعد المطرد فى نسبة الفقر المدقع فى مصر خلال الفترة (1999/ 20002018/2017)، حيث أن نسبة الفقر المدقع فى مصر قد بلغت أقصاها فى نهاية الفترة عام 2018/2017 لتصل إلى نحو 6.2\% بينما بلغت أدناها عام 1999/2000 لتصل إلى نحو2.9 \% فقط، حيث شهدت الفترة (1999- 2008) زيادة فى نسبة الفتر المدقع ثم أخذت فى التراجع خلال الفترة (2010- 2012) لتبلغ 


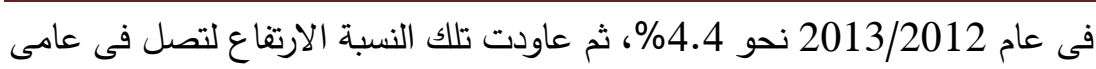
2015 2016، 2018/2017 إلى نحو 5.3\%، 6.2 \% \% على الترتيب، ويلاحظ أن هذه النسبة كانت متقاربة إلى حد كبير فى عامى 2009/2008، 2018/2017

شكل رقم (3)

نسبة الفقر المدقع فى مصر خلال الفترة (2000/1999- 2018/2017)

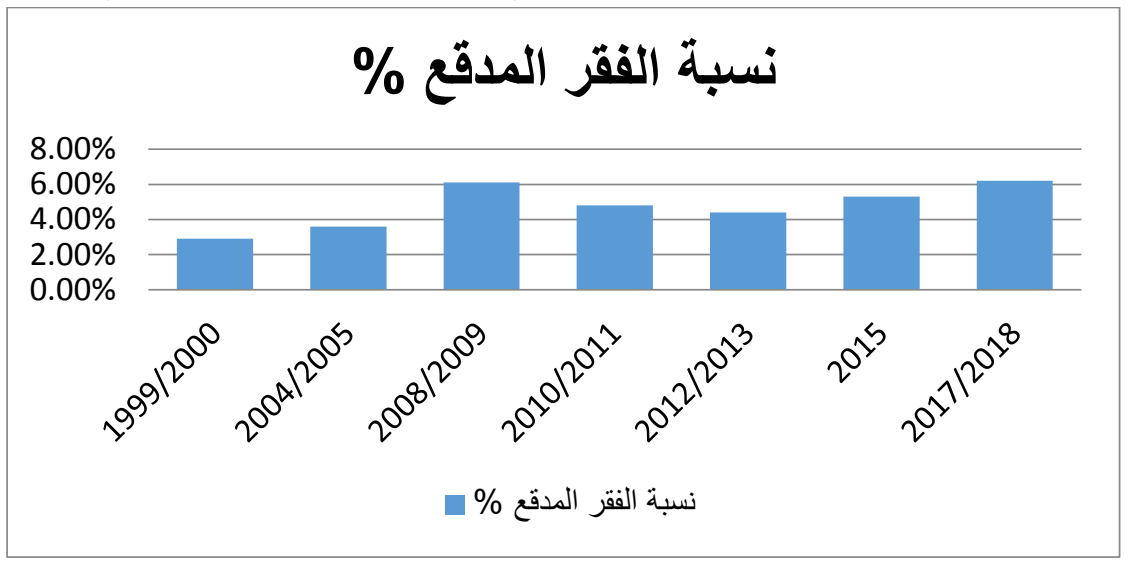

المصدر:إعتماداً على بيانات الجهاز المركزى للتعبئة العامة و الإحصاء - مسح الدخل و الإنفاق والإستهلاك - سنوات متعددة: * أن خط الفقر المدقع يتراوح بين 65\% و 70\% من خط الفقر المادى، مع اختلافات

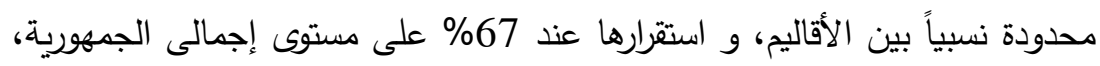
حيث أن ربف الحدود أعلى قيمة من حيث خط الفقر المدقع حيث بلغ نحو 6305 جنيه مصرى، و تلى ذلك المحافظات الحضرية حيث بلغ خط الفقر المدقع نحو 6065 جنيه مصرى، ثم جاء بعد ذلك حضر الحدود ليبلغ نحو 5924 جنيه مصرى، ثم جاء

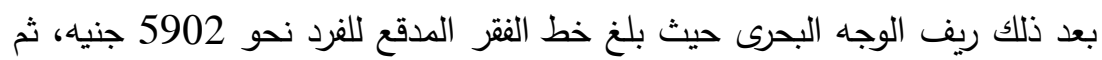
جاء ريف الوجه القبلى ليبلغ خط الفقر المدقع نحو 5896 جنيه، ثم جاء خط الفقر

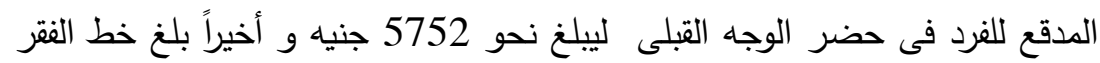

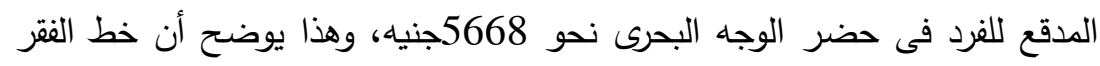




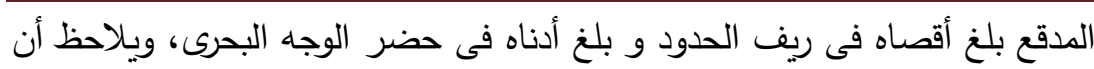

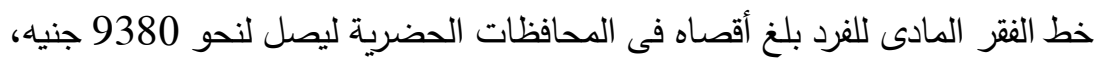

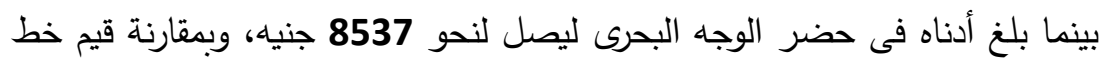

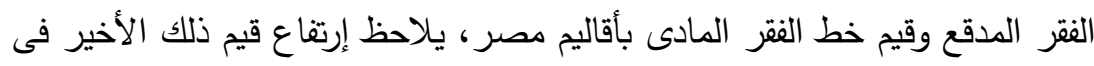
جميع أقاليم مصر (شكل رقم 4).

شكل رقم(4) مقارنة خط الفقر المادى و المدقع فى أقاليم مصرطبقاً

\section{لتعداد 2017/ 2018}

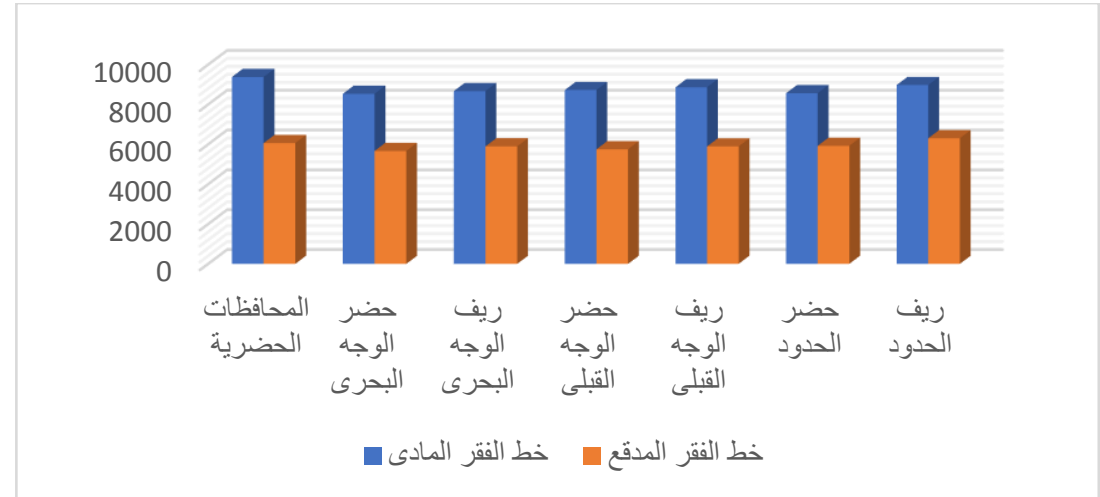

المصدر: إعتماداً على بيانات الجهاز المركزى للتعبئة العامة و الإحصاء - مسح

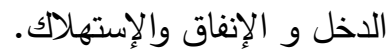

\section{* أبعاد مشكلة الفقر فى مصر:-}

تتجلى الأبعاد الاقتصادية لظاهرة الفقر فى تدهور القوة الثرائية للعملة المحلية و

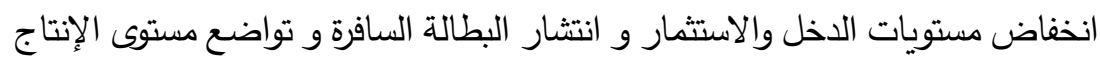
و الارتفاع النسبى فى الطاقات العاطلة، والنمو غير المتناسب للسكان، و من أهم الأبعاد الاجتماعية للفتر سوء توزيع الاخل وارتفاع نسبة الأمية وانتشارالعادات والتقاليد

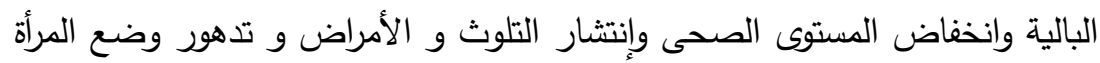
و انخفاض قدرتها على المشاركة الاجتماعية و الاقتصادية مما يعنى ارتفاع مستوى الإعالة فى المجتمع، فضلاً عن شيوع العنف والتطرف. 


\section{القسم الثالث}

\section{تحليل ظاهرة الفقر و تطورها ومحداتها فى مصر}

\section{خلال الفترة (2000/1999- 2018/2017).}

يلاحظ أنه بعد سنوات من النمو المتباطئ بعد عام 2011، بدأ تعافى الاقتصاد المصرى

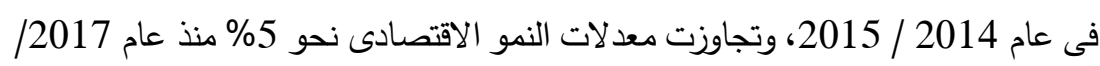

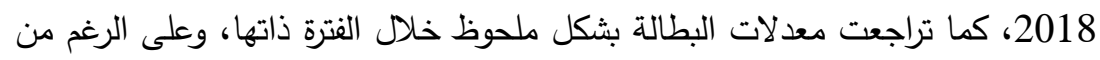
ذللك، فقد أظهرت نتائج بحث الدخل والإنفاق و الإستهلاك للأسر المصرية في عام 2017

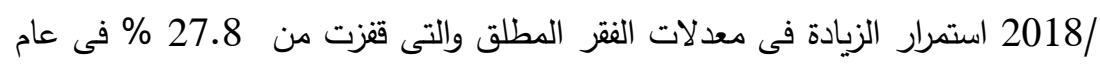

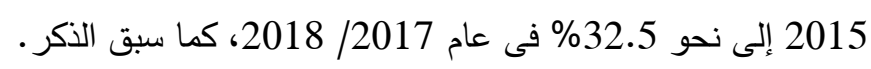

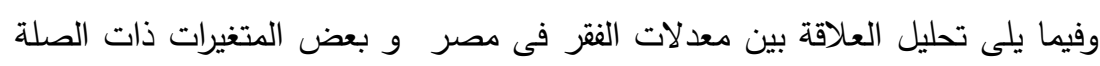

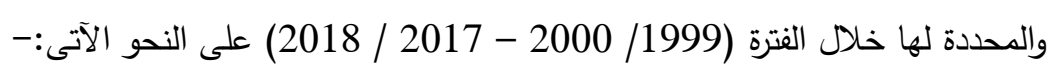

\section{1- العلاقة بين نسبة الفقر ومعدلات النمو الاقتصادى :-}

يتضح من استقراء البيانات الواردة بالجدول رقم (1)، أن معدلات الفقر بلغت أدناها خلال

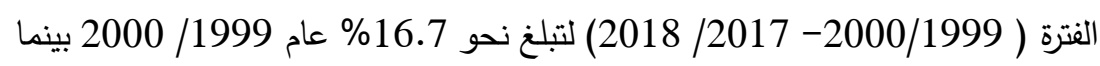
بلغت أقصاها فى عام 2018/2017 لتصل إلى نحو 32.5\% كما سبق الذكر ، و يلاحظ أن معدلات الفقر قد أخذت إتجاهاً تصاعدياً نحو الارتفاع بشكل دائم رغم أن هذا كان أنان

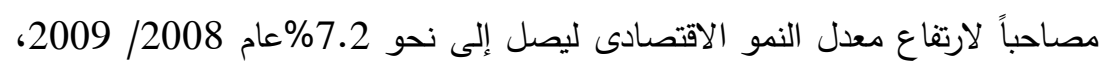

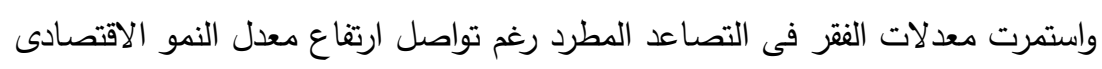

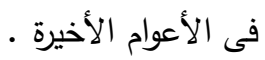

ويلاحظ أنه من بين هؤلاء الفقراء زاد عدد ونسبة الفقراء المدقعين ليصلوا إلى نحو 6

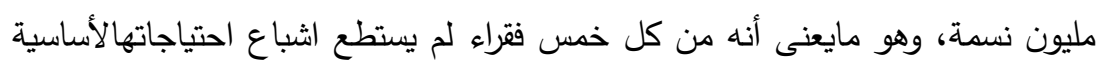
وخاصة الحاجات الغذائية. وهنا يلاحظ أن الوضع الحالى للفقر فى مصر يطرح تساؤلاً حول إمكانية تفسير

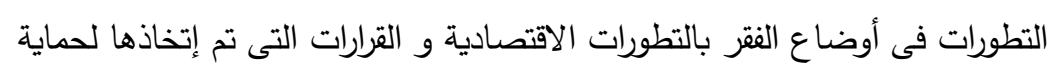




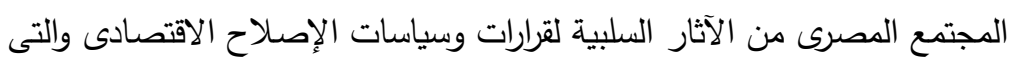

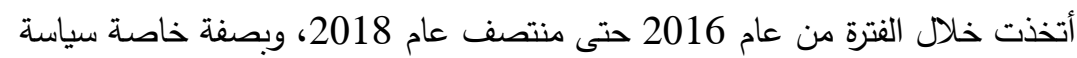
تحرير سعر الصرف فى عام 2016 و سياسات ترشيد الدعم السلعى والنقدى . ومن ثم كان للقرارات التى تم إتخاذها تطورات إيجابية عند الحديث عن العلاقة بين معدلات الفقر ومعدلات النمو الاقتصادى فى مصر خلال الفترة المذكورة حيث زادت

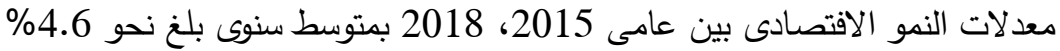
ومن المتوقع إستمرار تزايده (جدول رقم 1، شكل رقم 5) جدول رقم (1)

العلاقة بين نسبة الفقر و معدل النمو الاقتصادى خلال الفترة 2000/1999\% 2018/2017

\begin{tabular}{|c|c|c|}
\hline معدل النمو الالاقتصادى\% & نسبة الفقر \% & السنة \\
\hline$\% 6.1$ & \%16.7 & $2000 / 1999$ \\
\hline$\% 6.4$ & - & $2001 / 2000$ \\
\hline$\% 3.5$ & - & $2002 / 2001$ \\
\hline$\% 2.4$ & - & $2003 / 2002$ \\
\hline$\% 3.2$ & - & $2004 / 2003$ \\
\hline$\% 4.1$ & \%19.6 & $2005 / 2004$ \\
\hline$\% 4.4$ & - & $2006 / 2005$ \\
\hline$\% 6.8$ & - & $2007 / 2006$ \\
\hline$\% 7.1$ & - & 2008/2007 \\
\hline$\% 7.2$ & $\% 21.6$ & $2009 / 2008$ \\
\hline$\% 4.7$ & - & $2010 / 2009$ \\
\hline$\% 5.1$ & $\% 25.2$ & $2011 / 2010$ \\
\hline$\% 1.8$ & - & $2012 / 2011$ \\
\hline$\% 2.2$ & $\% 26.3$ & $2013 / 2012$ \\
\hline$\% 2.2$ & - & $2014 / 2013$ \\
\hline$\% 2.9$ & - & $2015 / 2014$ \\
\hline$\% 4.4$ & $\% 27.8$ & $2016 / 2015$ \\
\hline
\end{tabular}




\begin{tabular}{|c|c|c|}
\hline 2020/11/1 العلاقة بين الفقر والنمو الاقتصادي & 2017/2016 \\
\hline \hline & - & \\
\hline \%4.4 تاريخ قبول النشان محمد عبد اللطيف| & & \\
\hline \%4.2 & & $2018 / 2017$ \\
\hline
\end{tabular}

المصدر: قاعدة بيانات البنك الدولى شكل رقم (5) العلاقة بين نسبة الفقر و معدل النمو الاقتصادى فى

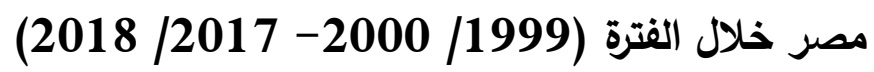

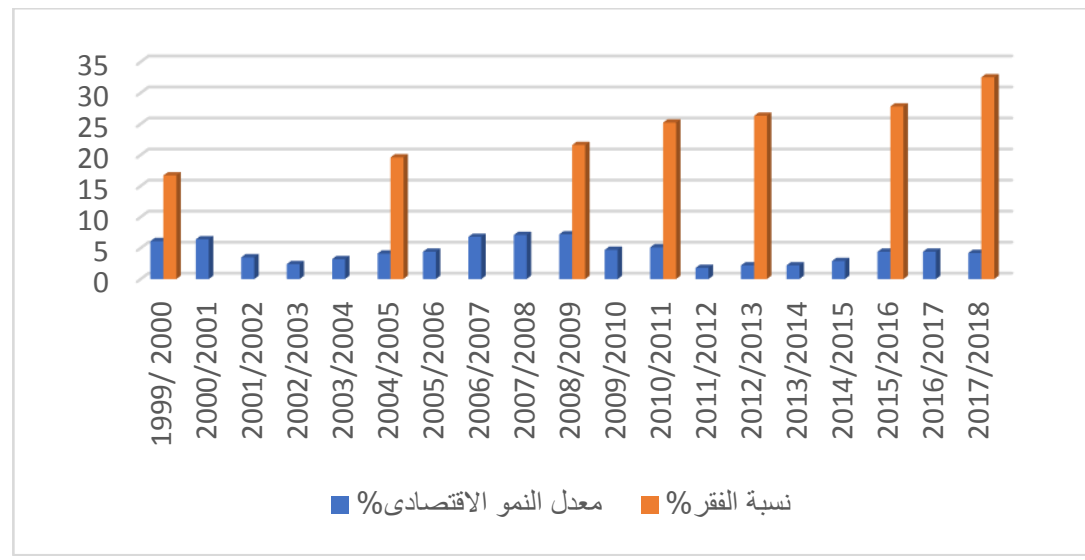

المصدر: إعتماداً على البيانات الواردة يالجدول رقم (1).

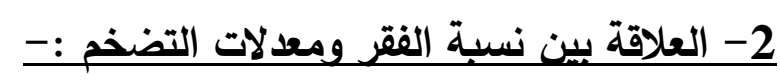

يتضح من استثراء البيانات الواردة بالجدول رقم(2)، العلاقة الطردية بين معدل الفقر و

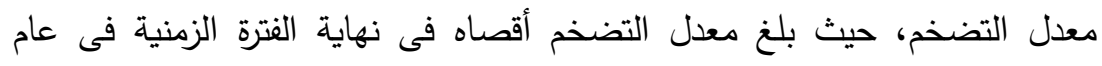

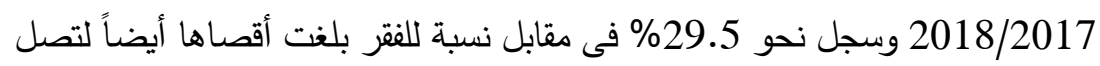
إلى نحو 32.5\%، ويلاحظ أن ارتفاع معدلات التضخم خلال هذه الفترة إنما يرجع

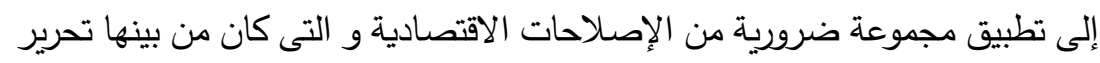

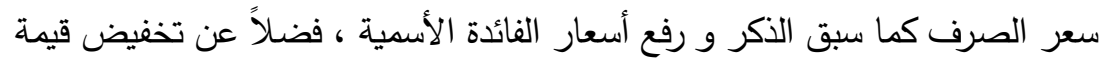
الدعم على المحروقات و ارتفاع أسعار الكهرباء و إصدار قانون ضريبة القيمة

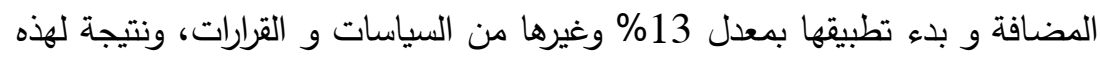




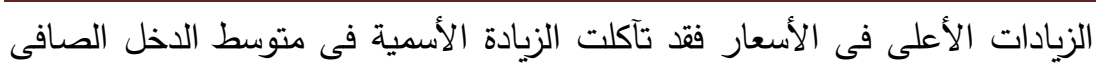

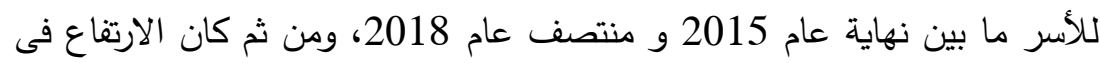

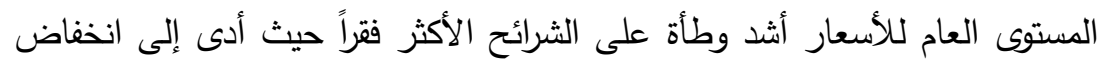

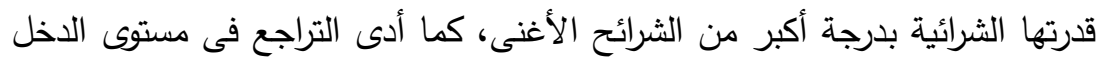

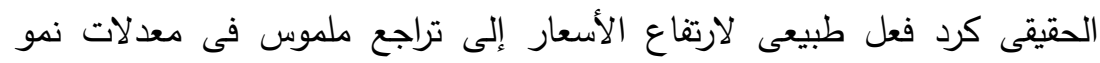

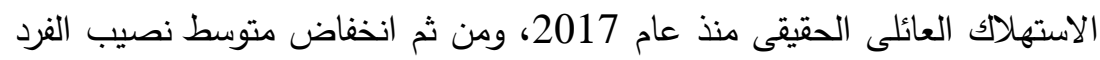

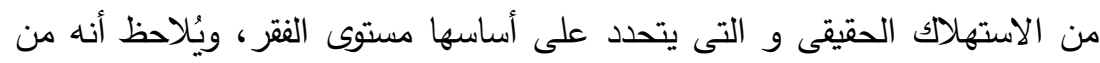
الآثار السلبية لقرارات وسياسات الإصلاح الاقتصادى والتى أتخذت خلال الفترة من التصني عام 2016 حتى منتصف عام 2018، الارتفاع الثديد والواضح فى تكلفة المعيثة نتيجة للارتفاع الحاد فى مستوى أسعار السلع الغذائية، حيث أنه رغم تراجع معدلات التضخم فيما بين آخر عام 2015 ومنتصف 2018، فقد ارتقع متوسط مستوى الأسعارإلى نحو 59\% بينما ارتفعت أسعار السلع الغذائية كسلع أساسية إلى نحو

$$
\text { 72\% ( جدول رقم2، شكل رقم 6). }
$$

جدول رقم (2) العلاقة بين نسبة الفقر ومعدل التضخم فى مصرخلال $\%$ الفترة (1999/ 2000 - 2017 / 2018 ( 2017

\begin{tabular}{|c|c|c|}
\hline معدل التضخم \% & نسبة الفقر \% & السنة \\
\hline$\% 3.1$ & $\% 16.7$ & $2000 / 1999$ \\
\hline$\% 2.7$ & & $2001 / 2000$ \\
\hline$\% 2$ & & $2002 / 2001$ \\
\hline$\% 2.4$ & & $2003 / 2002$ \\
\hline$\% 5.8$ & & $2004 / 2003$ \\
\hline$\% 16.3$ & $\% 19.6$ & $2005 / 2004$ \\
\hline$\% 4$ & & $2006 / 2005$ \\
\hline$\% 7.3$ & & $2007 / 2006$ \\
\hline$\% 10.4$ & & $2008 / 2007$ \\
\hline
\end{tabular}




\begin{tabular}{|c|c|c|}
\hline تاريخ قبول النشر 2020/11/1 & د. ايمان محمد عبد اللطيف & العلاقة بين الفقر والنمو الاقتصادي \\
\hline \%19.1 & $\% 21.6$ & $2009 / 2008$ \\
\hline$\% 11.8$ & & $2010 / 2009$ \\
\hline$\% 11.1$ & $\% 25.2$ & $2011 / 2010$ \\
\hline$\% 10.5$ & & $2012 / 2011$ \\
\hline$\% 7.3$ & $\% 26.3$ & $2013 / 2012$ \\
\hline$\% 10.3$ & & $2014 / 2013$ \\
\hline$\% 10.1$ & & $2015 / 2014$ \\
\hline$\% 10.6$ & $\% 27.8$ & $2016 / 2015$ \\
\hline$\% 14.5$ & & $2017 / 2016$ \\
\hline$\% 29.5$ & $\% 32.5$ & $2018 / 2017$ \\
\hline
\end{tabular}

المصدر: قاعدة بيانات البنك الدولى

شكل رقم (6) العلاقة بين نسبة الفقر و معدل التضخم فى مصر

خلال الفترة (1999/ 2000- 2018/2017)

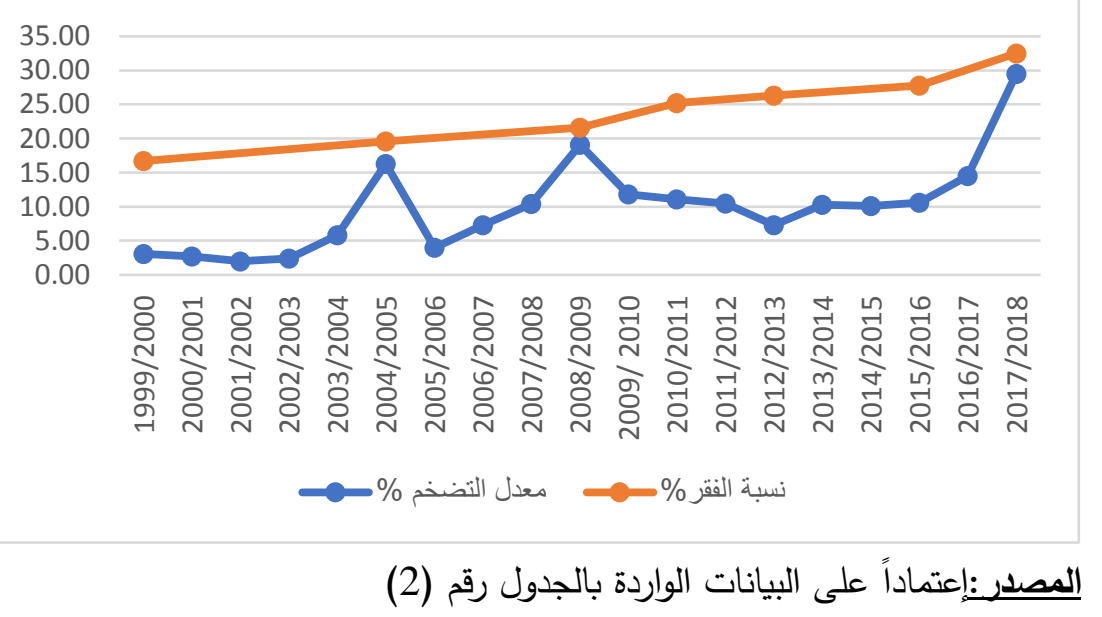




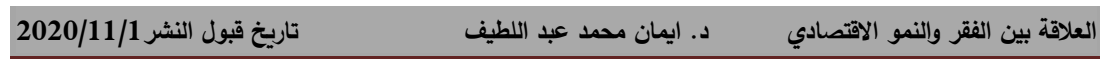

3-العلاقة بين نسبة الفقر و معدلات البطالة :-

يتضح من استعراض تطورات معدلات البطالة و الفقر، ضعف العلاقة الإرتباطية

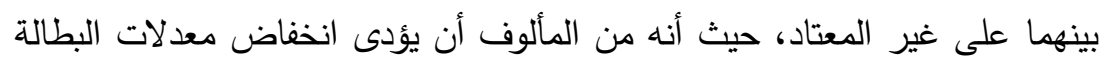
إلى تراجع معدلات الفقر • ولكن يُلاحظ فى الحالة المصرية إتجاه معدلات البطالة للانخفاض فى الأعوام الأخيرة، ورغم ذلك استمرت معدلات الفقر في الارتفاع، فعند

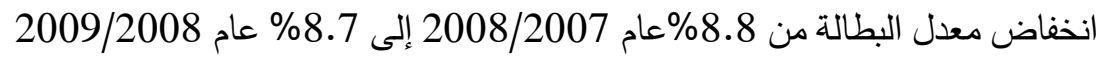
بلغت نسبة الفقر فى العام الأخير نحو 21.6\% وكذلك مألك عند انخفاض معدل البطالة

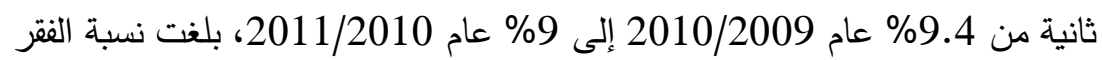
فى العام الأخير نحو 25.2\%، وكذلك عندما انخفض معدل البطالة من 13\% عام عام

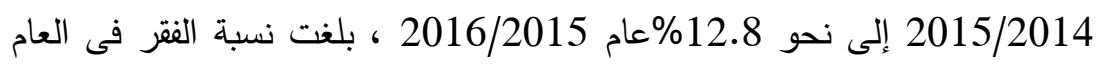

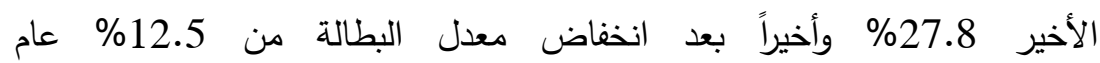
2017/2016إلى نحو 11.8\% عام 2018/2017 ، فقد بلغت نسبة الفقر فى العام الأخير نحو 32.5\%( جدول رقم 3 ، شكل رقم 7)

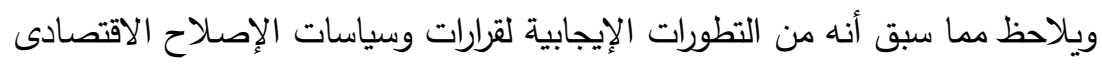

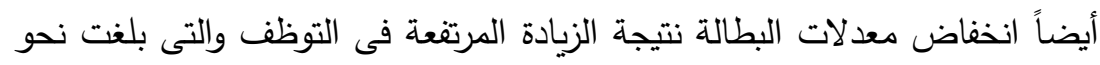

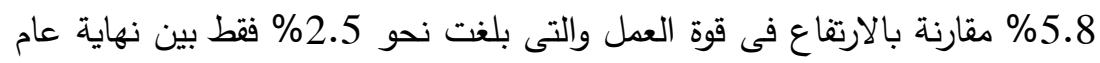

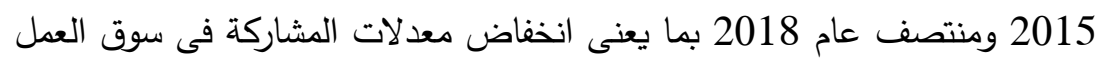

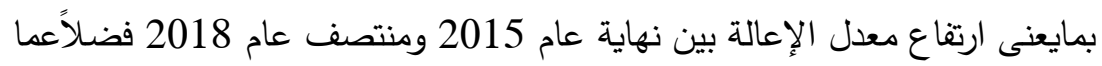

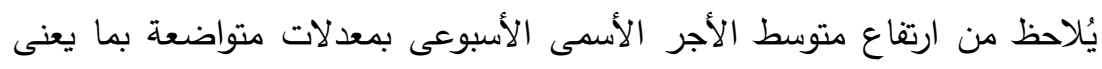

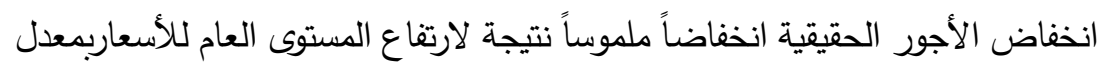

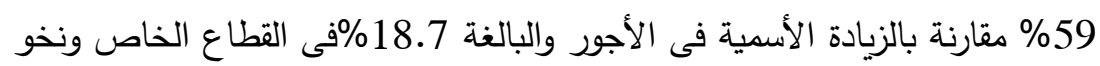

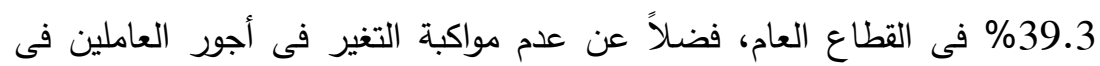

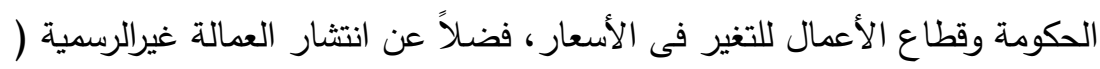
جدول رقم 3 ، شكل رقم 7) - (7) 
وخلاصة القول بأنه رغم ارتفاع معدلات النمو الاقتصادى وانخفاض معدلات البطالة،

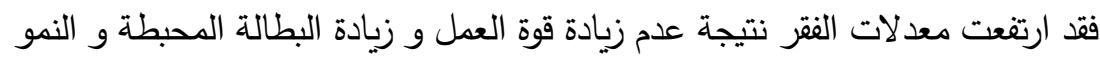

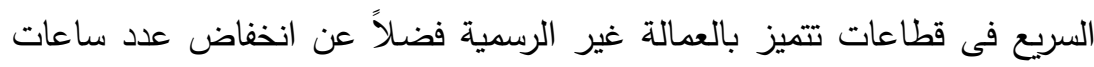

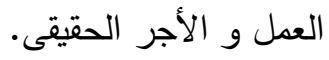

جدول رقم (3) العلاقة بين نسبة الفقر و معدل البطالة فى مصر خلال الفترة (1999/ 2000- 2017 / 2018)

\begin{tabular}{|c|c|c|}
\hline معدل البطالة\%\% & نسبة الفقر\%\% & السنة \\
\hline$\% 7.95$ & \%16.7 & $2000 / 1999$ \\
\hline$\% 9$ & - & $2001 / 2000$ \\
\hline$\% 9.2$ & - & $2002 / 2001$ \\
\hline$\% 10.2$ & - & $2003 / 2002$ \\
\hline$\% 11$ & - & $2004 / 2003$ \\
\hline$\% 10.3$ & \%19.6 & $2005 / 2004$ \\
\hline$\% 11.2$ & - & $2006 / 2005$ \\
\hline$\% 10.5$ & - & $2007 / 2006$ \\
\hline$\% 8.8$ & - & $2008 / 2007$ \\
\hline$\% 8.7$ & $\% 21.6$ & $2009 / 2008$ \\
\hline$\% 9.4$ & - & $2010 / 2009$ \\
\hline$\% 9$ & $\% 25.2$ & $2011 / 2010$ \\
\hline$\% 12$ & - & $2012 / 2011$ \\
\hline 12.7 & $\% 26.3$ & $2013 / 2012$ \\
\hline$\% 13.2$ & - & $2014 / 2013$ \\
\hline$\% 13$ & - & $2015 / 2014$ \\
\hline$\% 12.8$ & $\% 27.8$ & $2016 / 2015$ \\
\hline$\% 12.5$ & - & $2017 / 2016$ \\
\hline$\% 11.8$ & $\% 32.5$ & $2018 / 2017$ \\
\hline
\end{tabular}

المصدر: قاعدة بيانات البنك الدولى 
شكل رقم (7) العلاقة بين نسبة الفقر و معدل البطالة فى مصر خلال الفترة (2000/1999 - 2017/ 2018)

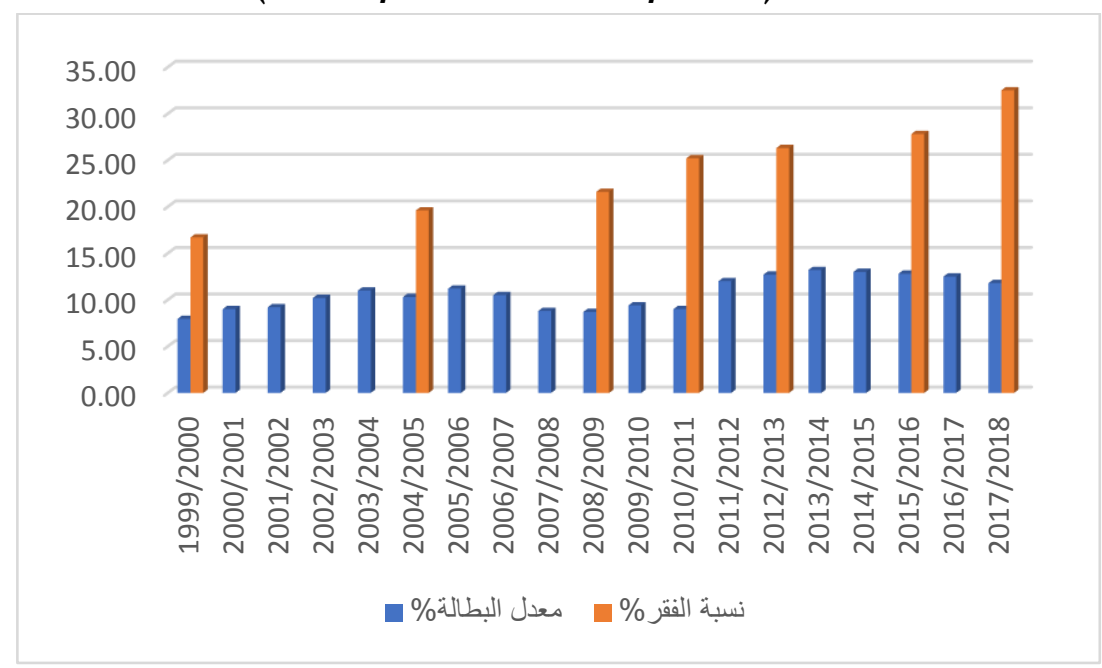

المصدر: إعتماداً على البيانات الواردة بالجدول رقم (3)

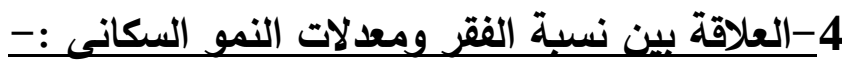

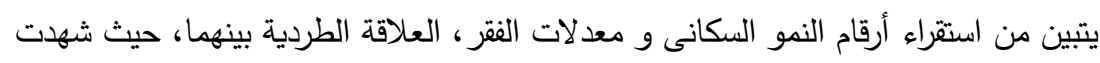

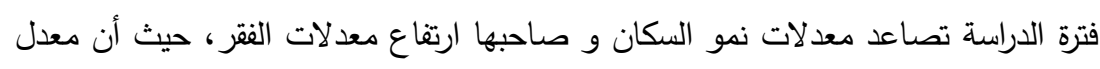

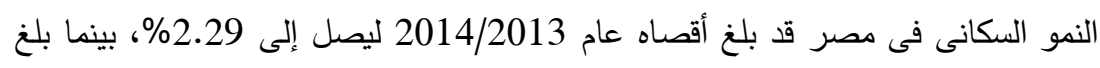

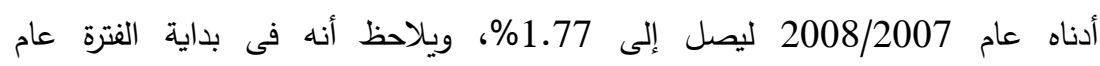

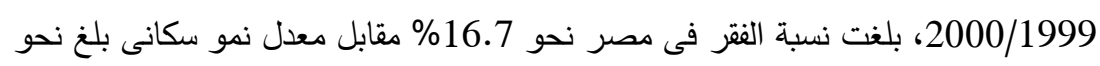

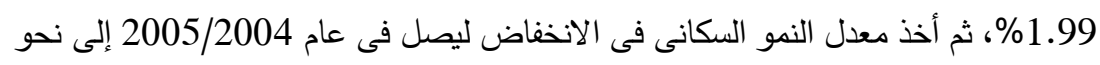

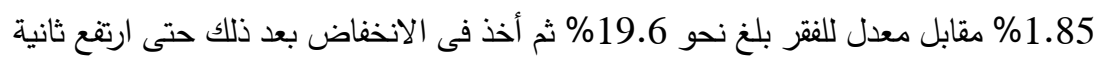

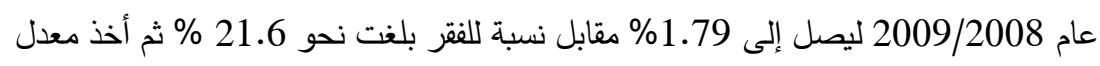

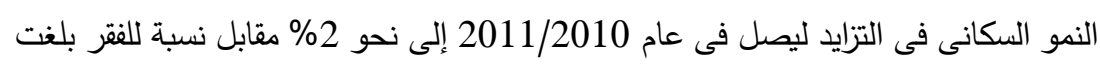

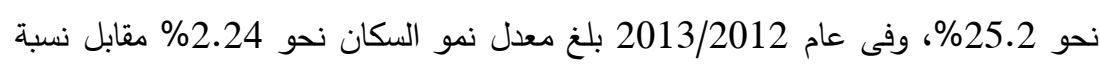
للفتر بلغت نحو 26.3\%، وفى عام 2516/2015 رغم عام انخفاض معدل النمو السكانى مقارنة 
بنظيره فى العام السابق مباشرة ليصل إلى نحو 23.23\%، فقد زادت نسبة الفقر لتبلغ نحو 27.8\%، وفى نفس الإتجاه فقد انخفض معدل النمو السكانى فى عام 2018/2017 مقارنة بالعام السابق له 2017/2016 ليبلغ نحو 2.11\% مقابل نسبة مرتفعة للفقر بلغت نحو 32.5 \% (جدول رقم 4، شكل رقم 8).

جدول رقم (4) العلاقة بين نسبة الفقر ومعدل النمو السكانى فى رهى مصرخلا ل الفترة (1999/ 2000- 2018) 2017)

\begin{tabular}{|c|c|c|}
\hline معدل النمو السكانى\% & نسبة الفقر \% & السنة \\
\hline$\% 1.99$ & $\% 16.7$ & $2000 / 1999$ \\
\hline \%1.95 & & $2001 / 2000$ \\
\hline$\% 1.92$ & & $2002 / 2001$ \\
\hline$\% 1.90$ & & $2003 / 2002$ \\
\hline \%1.88 & & $2004 / 2003$ \\
\hline$\% 1.85$ & \%19.6 & $2005 / 2004$ \\
\hline$\% 1.82$ & & $2006 / 2005$ \\
\hline$\% 1.79$ & & $2007 / 2006$ \\
\hline \%1.77 & & $2008 / 2007$ \\
\hline$\% 1.79$ & $\% 21.6$ & $2009 / 2008$ \\
\hline \%1.88 & & $2010 / 2009$ \\
\hline$\% 2$ & $\% 25.2$ & $2011 / 2010$ \\
\hline$\% 2.14$ & & $2012 / 2011$ \\
\hline$\% 2.24$ & $\% 26.3$ & $2013 / 2012$ \\
\hline$\% 2.29$ & & $2014 / 2013$ \\
\hline$\% 2.28$ & & $2015 / 2014$ \\
\hline$\% 2.23$ & $\% 27.8$ & $2016 / 2015$ \\
\hline$\% 2.17$ & & $2017 / 2016$ \\
\hline$\% 2.11$ & $\% 32.5$ & $2018 / 2017$ \\
\hline
\end{tabular}

المصدر: قاعدة بيانات البنك الدولى 
شكل رقم (8) العلاقة بين نسبة الفقر و معدل النمو السكانى فى مصر خلال الفترة (1999/ 2000- 2017/ 2018)

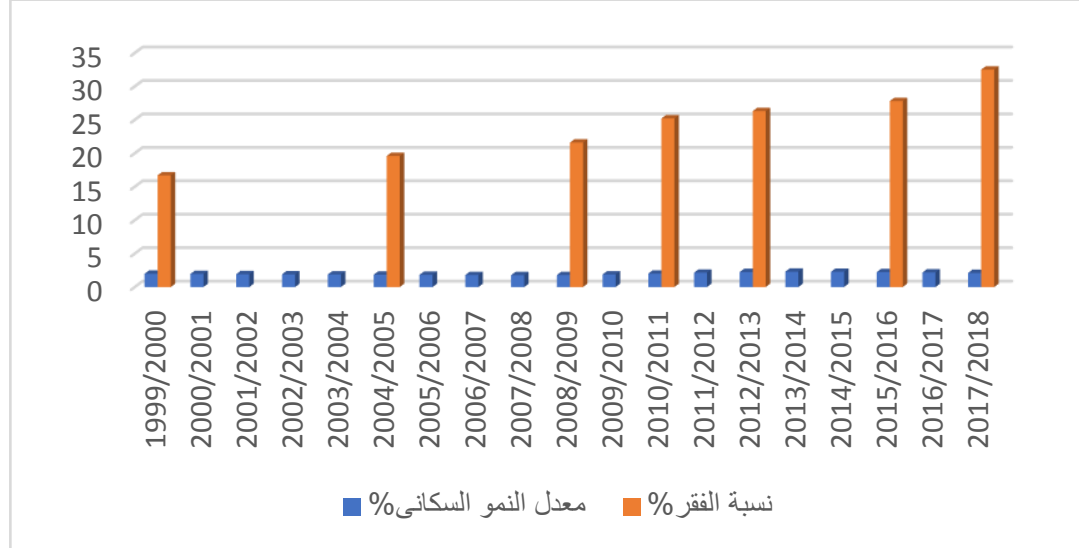

المصدر: إعتماداً على البيانات الواردة بالجدول رقم (4)

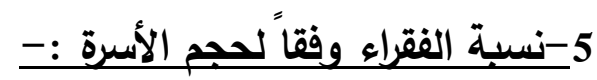

قد أفاد تحليل خريطة الفقر، ارتفاع معدل الفقر فى المحافظات و المراكز والقرى التى

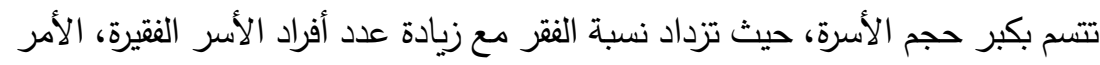

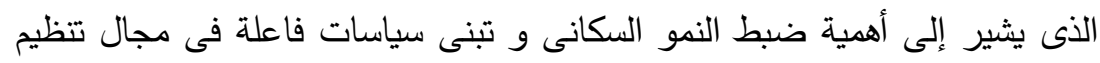

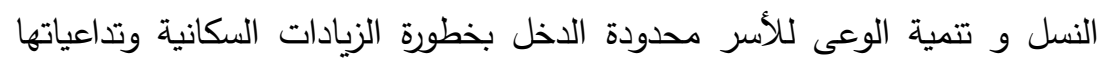
السلبية على مستويات المعيثة، حيث يلاحظ مايلى (جدول رقم 5، شكل رقم 9): أ- تزايد نسبة الفقراء مع زيادة حجم الأسرة. ب-أن نحو 7\% فقط من الأفراد الذين يعيشون فى أسر بها أقل من 4 أفراد هم من

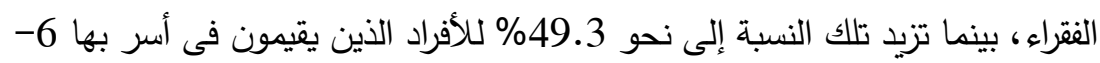
( - 7 ج- أن نحو 76\% من الأفراد الذين يعيشون فى أسر بها 10 أفراد أو أكثر هم من الفقراء. 


\begin{tabular}{|c|c|c|}
\hline تاريخ قبول النشر 2020/11/1 & د. ايمان محمد عبد اللطيف & العلاقة بين الفقر والنمو الاقتصادي \\
\hline
\end{tabular}

جدول رقم (5)

\begin{tabular}{|c|c|}
\hline نسبة الفقراء \% & حجم الأسرة \\
\hline$\% 7$ & $1-3$ \\
\hline$\% 25.9$ & 4-5 \\
\hline$\% 49.3$ & $6-7$ \\
\hline$\% 73$ & $8-9$ \\
\hline$\% 75.8$ & $10+$ \\
\hline$\% 32.5$ & الجملة \\
\hline
\end{tabular}

المصدر: الجهاز المركزى للتعبئة العامة و الإحصاء، بحث الدخل و الإنفاق، 2017

\section{شكل رقم (9)}

نسبة الفقراء وفقاً لحجم الأسرة

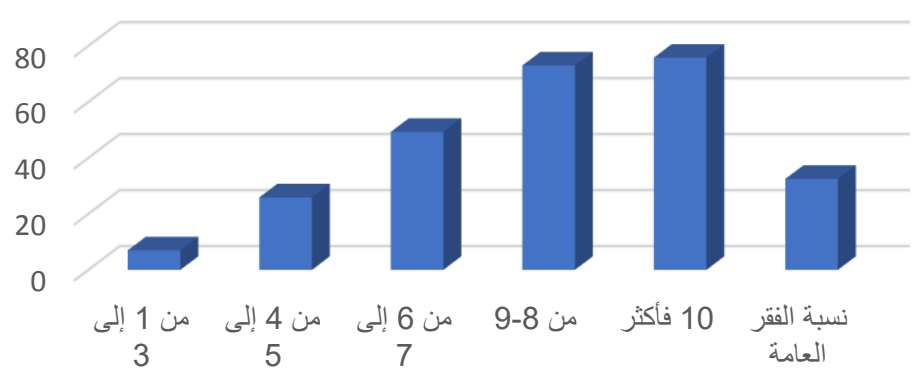

المصدر :إعتماداً على البيانات الواردة بالجدول رقم (5) 


\section{6-نسبة الفقراء وفقاً للحالة التعليمية :--}

يتضح من الأرقام الموضحة بالجدول رقم ( 6 ) والثكل رقم (10)، أن انخفاض

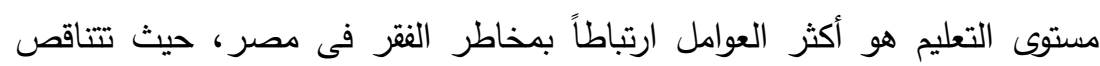

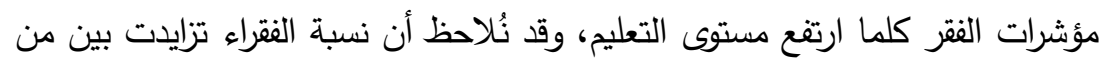

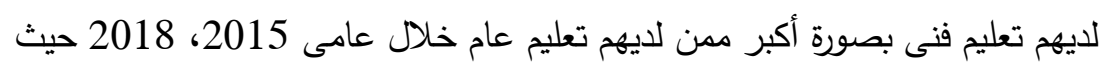

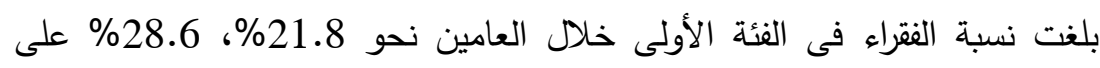
الترتيب مقارنة بنسبة الفقراء فى الفئة الثانية عن نفس العامين والتى بلغت نحو نحو

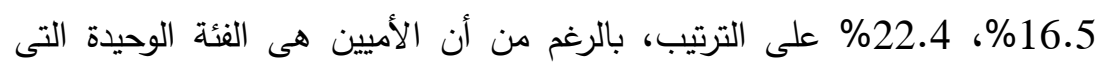

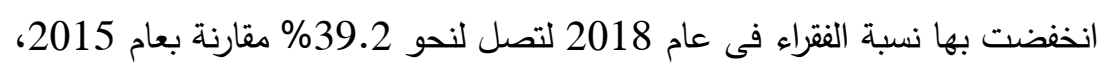

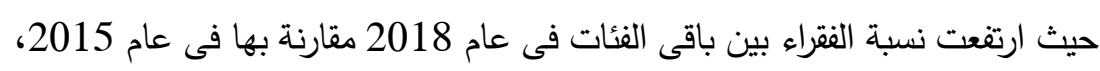

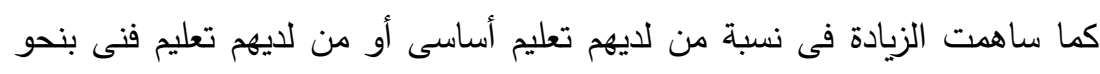

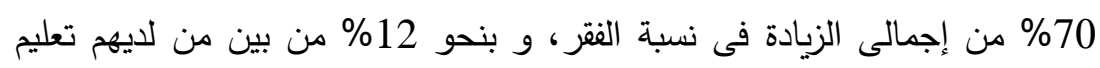

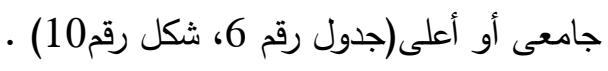

جدول رقم (6) نسبة الفقراء وفقاً للحالة التعليمية \%

\begin{tabular}{|c|c|c|c|c|c|c|c|}
\hline شامعادة & شلهاد ألجادة & شنهاديم & ثانعانيم & شعليم & يكترأ و & أمى & 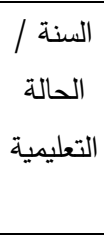 \\
\hline 6.7 & 11.4 & 21.8 & 16.5 & 32.6 & 32.5 & 40.3 & 2015 \\
\hline 11.5 & 20.1 & 28.6 & 22.4 & 38.3 & 37.5 & 39.2 & 2018 \\
\hline
\end{tabular}

المصدر: الجهاز المركزى للتعبئة العامة و الإحصاء، مسح الدخل و الإنفاق و

الإستهلاك 
شكل رقم (10) نسبة الفقراء وفقاً للحالة التعليمية

النسبة المئوية لمستوى التعليم للفقراء

50

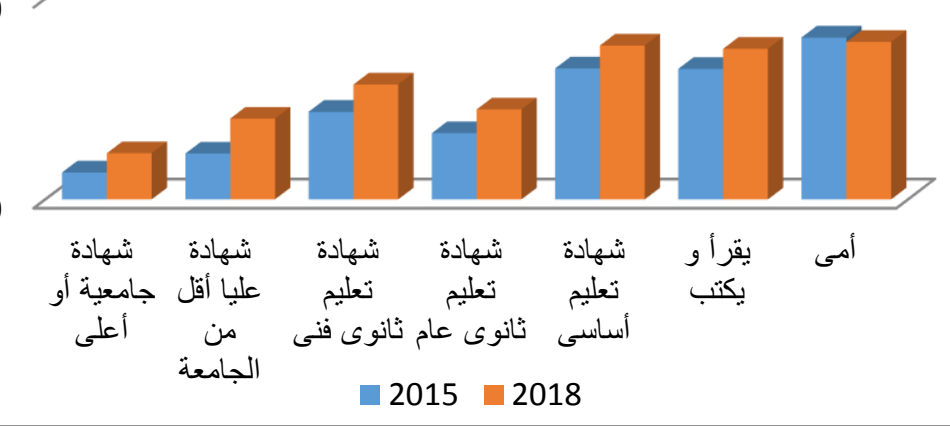

المصدر: إعتماداً على البيانات الواردة بالجدول رقم (6)

\section{القسم الرابع}

\section{تحليل وتقويم السياسات والاجراءات المطبقة لمواجهة مشكلة}

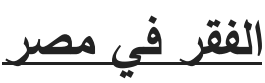

بداية فإن مثلث الفقر - النمو - عدم المساواة أو عدم العدالة فى توزيع الاخل يشيرفى مدي الاقتصاد التتموى، إلى فكرة مؤداها أن التغير فى مستويات الفقر فى أى دولة يمكن تحديده بالكامل من خلال تغيرات نمو الدخل و تغيرات عدم المساواة.

وهناك العديد من القرارات التى اتخذتها الحكومة المصرية للحد و التخفيف من حدة لديرة

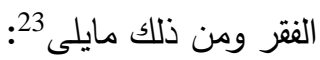

23 وز وارة التخطيط و التنمية الاقتصادية، ورقة عمل بعنوان " الفقز والنمو والتوظف". 


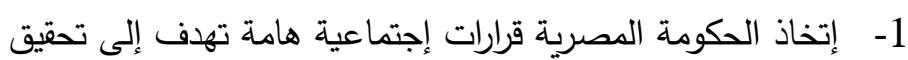

العدالةالاقتصادية و الحماية الإجتماعية بهدف التخفيف من الآثار السلبية

لبرنامج و إجراءات الإصلاح الاقتصادى على الأسر المصرية و التى تتمثل تلك القرارات الإجتماعية فى الآتى:

زيادة الدعم النقدى للفرد بصورة شهرية على بطاقات التموين بنسبة زيادة بلغت الإست

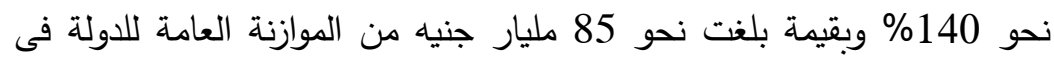
يونيو 2017

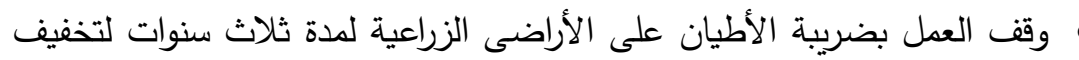
الأعباء الضرببية على القطاع الزراعى منذ يونيو 2017

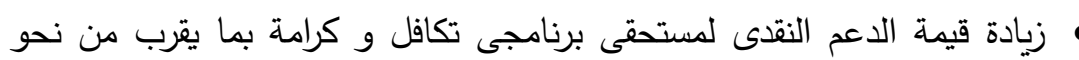
8.25 مليار جنيه من الموازنة العامة للدولة منذ يونيو 2017

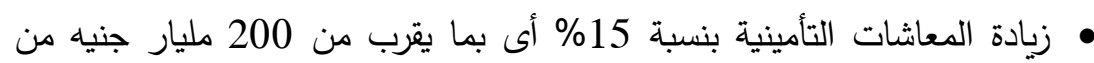
الموازنة العامة للدولة منذ يونيو 2017 إصدار شهادة أمان من جانب شركة مصر للتأمين بهدف توفير تغطية تأمينية

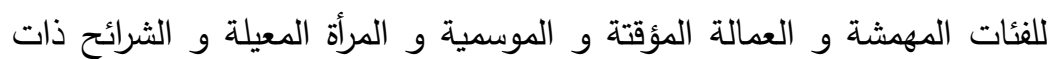
الاخول المحدودة منذ مارس 2018 2- ت تنفيذ عدد كبير من برامج الإسكان الإجتماعى و الذى صاحبه مبادرة تطوير

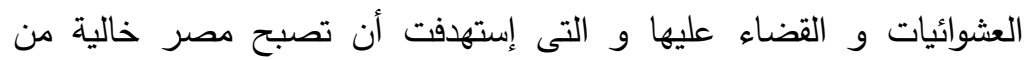
العشوائيات غير الآمنة و التى بلغ عددها نحو 357 منطقة عشوائية فى العام

$$
\text { الحالى عام } 2020 .
$$

3- زيادة مخصصات التحويلات النقدية من خلال برنامجى تكافل و كرامة و معاش

$$
\text { الضمان خلال الفترة (2012 / } 2013 \text { - 2018/ 2019). }
$$

4- إطلاق مبادرة المشروعات متتاهية الصغر و التى من أهدافها تحقيق التمكين الاقتصادى للمرأة المعيلة و الفئات الأكثر إحتياجاً وغيرها من الأهداف الهامة. 
5- العمل على تخفيض معدلات البطالة بشكل ملحوظ مابين عامى 2015، 2018

$$
\text { حيث بلغت على الترتيب نحو 12.8\%، }
$$

6- رفع معدلات النمو الاقتصادى بين عامى 2015، 6 2018 2018 بمتوسط سنوى بلغ نحو 4.6\% والمتوقع إستمرار ارتفاعه.

7- تستجيب مبادرة حياة كريمة لتكليفات السيد رئيس الجمهورية فى يناير 2019 و و التى وجه خلالها بالتتسيق بين الأجهزة المختلفة من أجل توفير حياة كريمة للفئات

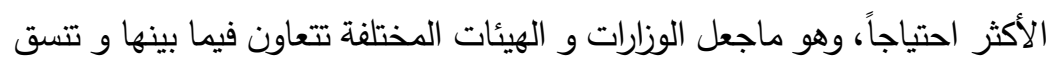

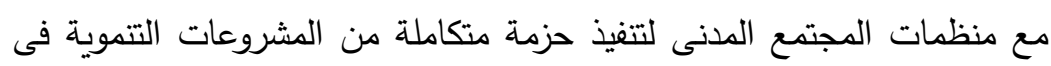
143 قرية خلال العام المالى 2019 / 2020 ليتم زيادة هذا العدد إلى 357 قرية منية

$$
\text { فى العام المالى 2021/2020. }
$$

\section{تقييم فعالية سياسة المساعدات الإجتماعية النقدية24:-}

1 - أدت مساعدات برنامج تكافل إلى خروج نحو 10\% من المستفيدين من تحت

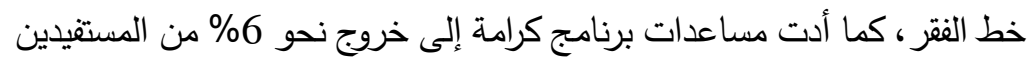
من دائرة الفقر ، أى ساعد البرنامجان على إنتثال نحو 91.

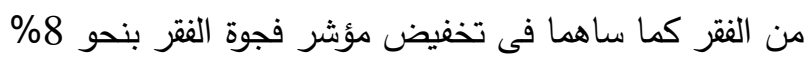

2الفقر أى انتثال مايقرب من نحو 1.2\% من المصريين من الفقر 3الإجتماعية (3.8\% من المسنيين والمعاقيين الفقراء فى ريف الصعيد إستفادوا

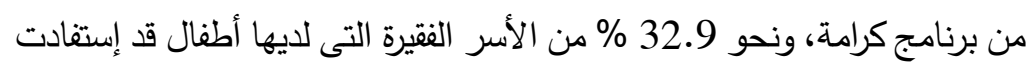

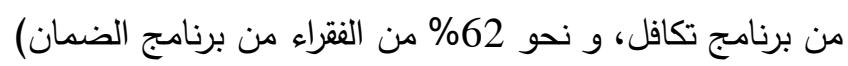


أى أن نحو 88.5\% من الأسر المصرية يتم تغطيتها فى منظومة الدعم الجديدة عام

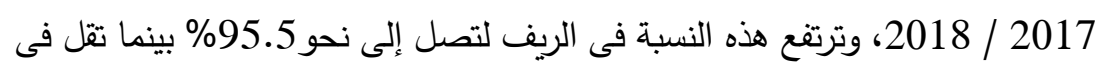

$$
\text { الحضر لتصل إلى نحو 80.2\% }
$$

\section{القسم الخامس}

\section{النتائج وتوصيات الدراسية}

أولاًا: النتائج:-

• أن ارتفاع معدلات التضخم خلال هذه الفترة إنما يرجع إلى تطبيق مجموعة

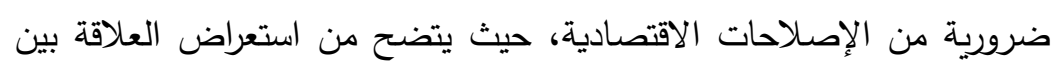

معدل الفقر و معدل التضخم العلاقة الطردية بينهما.

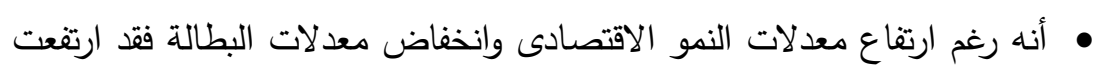
معدلات الفقر نتيجة انخفاض متوسط الاستهلاك الحقيقى للفرد مع ارتفاع تكلفة

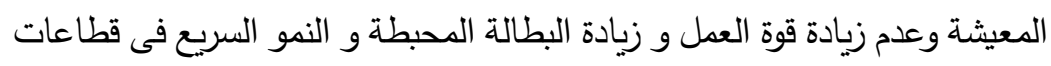
تتميز بالعمالة غير الرسمية وانخفاض عدد ساعات العمل و الأجر الحقيقى.

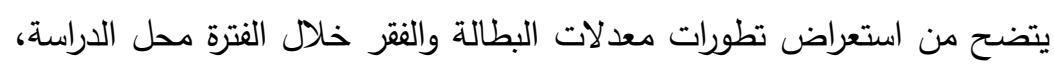

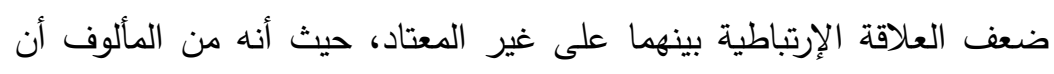

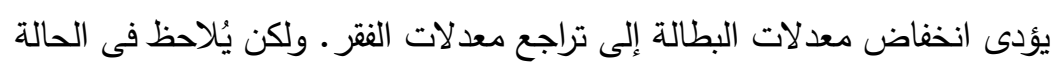

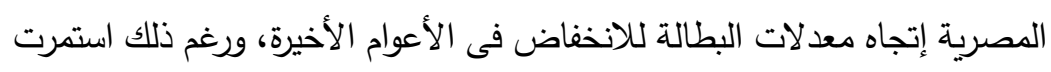

$$
\text { معدلات الفقر فى الارتفاع · معنداه }
$$

أنه من استقراء أرقام النمو السكانى و معدلات الفقرت ، تبين وجود علاقة طردية

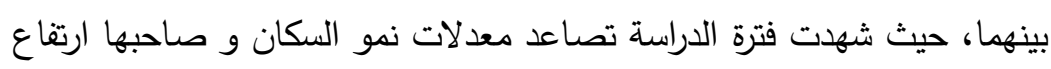

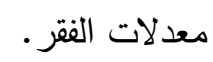

أن انخفاض مستوى التعليم هو أكثر العوامل ارتباطاً بمخاطر الفقر فى مصر ، حيث تتناقص مؤشرات الفقر كلما ارتقع مستوى التعليم. 


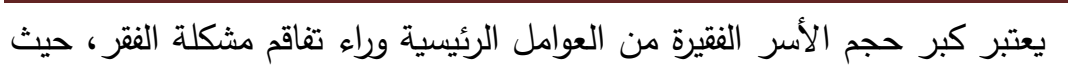

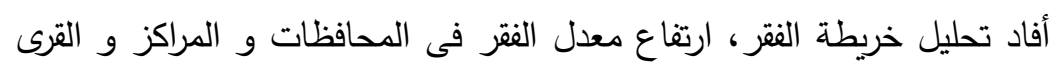

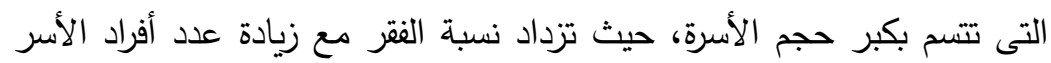

$$
\text { الفقيرة. }
$$

\section{ثانياً: التوصيات والسياسات المقترحة:-}

إعادة النظر فى بنود مايتم وضعه تحت مظلة الدعم و برامج الحماية الإجتماعية بحيث تقتصر تلك البنود على البرامج الهادفة بثكل أساسى لأغراض إجتماعية، وفئه والتى تستهدف الأسر الفقيرة.

• العمل على تحسين الخدمات العامة، وبصفة خاصة التعليم و الصحة و السكن الكريم بما يكفل الحد من الفقر متعّد الأبعاد، فضلاً عن توفير حياة كريمة للفقراء. • الحد من النمو السكانى و العمل على إصلاح المنظومة التعليمية لتجنب تدنى المستوى التعليمى ومخرجاته التى لاتتماشى ومتطلبات سوق العمل الحديثة، فضلاً

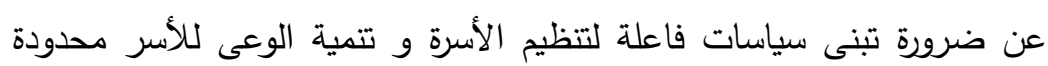

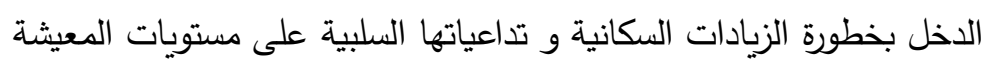

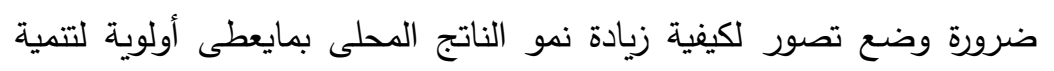
قطاعات الإنتاج السلعى (الزراعة و الصناعة) بمعنى أنه من غير المنطقى التركيز

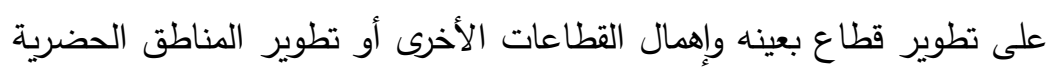
و إهمال المناطق الريفية. أهمية تكثيف الاستثمارات الموجهة لمحافظات الصعيد لتقليل التفاوتات الدخلية بين المحافظات.

ضرورة العمل على توفير نمو إحتوائى عند مستويات تسمح بنمو معقول فى الإستهلاك العائلى بما يضمن عدم إستمرار وقوع الفئات الضعيفة في دائرة الفقر . 
• ترشيد منظومة الدعم و رفع كفاءة التوزيع لتعظيم إستفادة الفئات الإجتماعية الأقل

$$
\text { دخلاً لأثرها الواضح على ميزانية الأسر الفقيرة. }
$$

ضرورة التركيز على نمط من النمو الإحتوائى يضمن خلق فرص عمل أكثر

و أفضل من أجل مشاركة جميع الإمكانيات البشرية فى مصر فى سوق العمل

$$
\text { و فى الإستفادة من النمو الاقتصادى. }
$$

العمل على توفير الحماية الإجتماعية للفقراء بما يعزز من قدراتهم للاخول فى الإسى

سوق العمل، وبما يؤدى إلى تقليل التفاوتات فى توزيع الدخل من خلال توفير

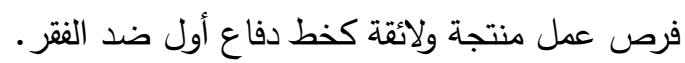

• التركيز على السياسات الرامية لرفع متوسط نصيب الفرد من الدخل القومى ومن

الاستهلاك الحقيقى وليس الناتج المحلى الاجمالى.

• ضرورة العمل على رفع كفاءة الموارد البشرية المتاحة فى المجتمع و رفع مستوى

التعليم و الإهتمام بالرعاية الصحية.

الأخذ بمبدأ المزايا النسبية و المزايا التتافسية و الإعتماد على القطاع الخاص و

تطوير سوق العمل وإنماء الصناعات الصغيرة والمغذية. 


\section{قائمة المراجع}

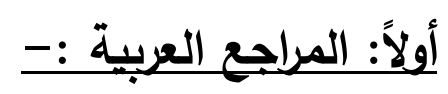

- أحمد، بوحزام سيد. 2017/ 2018، “لالنمو المحابى للفقراء فى الجزائر : دراسة

قياسية للفترة (1970 - 2016)"؛ رسالة دكتوراة، كلية العلوم الإقتصادية و التسيير و العلوم التجارية . . ـ السيد، زينب. 2015، "عدالة توزيع الدخل و النمو الإقتصادى : الحالة

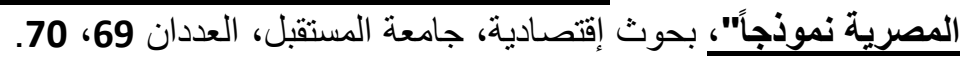

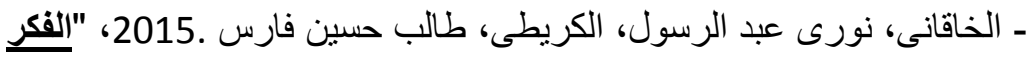

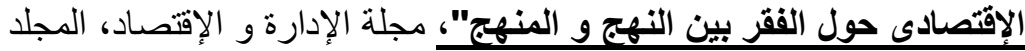

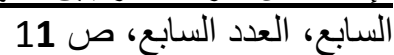
- الخطيب، أشرف يونس عبد الكريم. 2016، "العلاقة بين الفقر و النمو الإقتصادى فى فلسطين خلال الفترة (1995- 2014)"، كلية الإقتصاد و العلوم الإدارية، جامعة

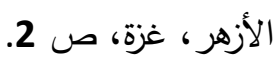
- العراقى، بثار. 2013، “لالسياسة المالية وهر، آليات تأثيرها فى معدلات الفقر”؛

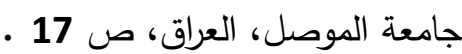
- النجار ، سعيد. 1973، " تاريخ الفكر الاقتصادى" ، دار النهضة المصرية - الهوارى، بن الحسن.2017، " الفقر و التفاوت فى توزيع الدخل فى الجزائر: دراسة قياسية للفترة (1980 - 2013)"، مجلة البثائر الإقتصادية، المجلد الثالث، العدد الثانى، ص ص 5 53- 54. - أمحمد،عر بوزيد. 2011 / 2012، “تمذجة ظاهرة الفقر في الجزائر"، أطروحة دكتوراة، جامعة تلمسان، ص صعر صرد 33- 34. 
- بن جلول ، خالد ـ 2017، "النمذجة القياسية لعلاقة النمو الإقتصادى بمعدلات الفقر فى الجزائر للفترة (1985 - 2015)" ، مجلة التنمية الاقتصادية ، المجلد رقم (2) ، العدد رقم (2) العزئ

- بن سنوسى، ليلى، جديد، مسعودة.2011، "الضرائب و آثارها على التنمية"، معهد

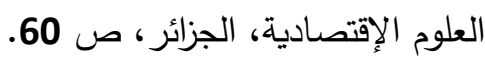

- خير الدين، هناء، الليث، هبة. 2006، "العلاقة بين النمو الإقتصادى و توزيع اللخل و الحد من الفقر فى مصرّ"، ورقة عمل رقم 115.

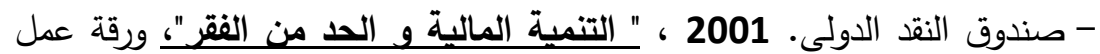
صادرة من.صندوق النقد الدولى، ص16.

- فطيمة، حاجى. 2014، "إثكالية الفقر فى الجزائر فى ظل البرامج التنموية: دراسية حالة الجزائر خلال الفترة (2005 - 2014)"؛ رسالة دكتوراة، جامعة محمد خيضر ، بسكرة، الجزائر، ص ص 13-16.

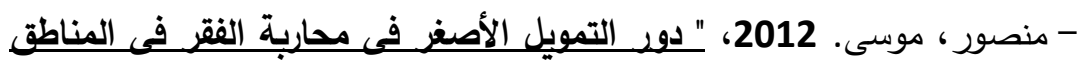
الريفية"، كلية العلوم الإقتصادية و التجارية، الجزائر ، صونس،

- وزارة التخطيط والتتمية الاقتصادية ، " الاقتصاد المصرى وتحدى الفقر" ، 13 أكتوبر 2019 . (2019 ثانياً: المراجع الأجنبية :-

- Ahlenius, H. 2011, "Pro - Poor Growth: Absolute and Relative Definition ".

- Aliona,J. 2017, "Pro - Poor Growth: Definition ; Measurement and Policy Issues".

- Angelique, G,Nindi, Nicholas, M and Odhiambo. 2015, "Poverty and Economic Growth in Swaziland: An 
Empirical Investigation", University of South Africa, Vol.13, No.1

- Brady, D. 2019, "Theories of the Causes of Poverty", Annual Review of Sociology ; Vol.45; PP: 155- 156.

- $\quad$ Breunig, R and Majeed; O.2020, "Inequality, Poverty andEconomic Growth",International Economics, Vol.161.

- Davis, E. and Sanchez, M. 2014, "AReview of the Economic Theories of Poverty", No.435, p. 20.

- Lee,N and Sissons, P .2016, "Inclusive Growth ? The Relationship Between Economic Growth and Poverty in British Cities", London School of Economics.

- Mohammed, T. 2018, "Simulation of the Impact of Economic Policies on Poverty and Inequality: GEM In Micro - Simulation for the ALGERIAN Economy", International Review of Applied Economics, Vol. 32, No. 3.

- Pressman, S. 1991, "Keynes and Antipoverty Policy", Taylor and Francis, Vol.49, No. 3.

- Sinn, H. W and Scand; J.1995, "ATheory of The Welfare State of Economics",University of Munich,Germany, Vol. 97, No.4.

- Tikhomova, N.2015,"The Structural Preconditions and Basic Types of Poverty in Russia", Sociological Research, Vol.54, Issue. 1.

- Tinbege,J; "On the Measurement of Welfare", Journal of Economics, Vol. 50, p7.

- Todaro,M and Smith,S , 2015.“Poverty; Inequality, and Development",New York and George Washington University, P.226.

- Verme,P.2010, "Astructural Analysis of Growth and Poverty in the Short Run", Journal of Developing Areas, Vol.43, No. 2, pp: 19- 23. 
The Relationship between the Poverty and the

Economic Growth with Application to the Egyptian

Case, during the Period from 1999/2000 to 2017/ 2018

Dr.Eman Mohamed Abdel-latif Mostafa

Lecturer at Department of Economics

Faculty of Administration, Economics and Information Systems

Misr University for Science and Technology

\section{Abstract:}

Poverty is a major obstacle to achieving sustainable development and raising economic growth rates. Therefore, all countries seek to adopt policies aimed at eradicating poverty and improving citizens' standard of living. The current study examines three problems:

- Despite the increase in investments directed to Upper Egypt governorates, the income gap is still there between the Upper Egypt governorates and other governorates.

- Although the national economy has grown at high rates, this is not commensurate with the poverty rates in the society.

- Despite the increase in government and non-profit spending on social protection projects and improving the incomes of the poor, this has not been sufficient to eradicate poverty.

Inference and Analysis are the two approaches employed in the current study. Moreover, the research is divided into five parts, the first of which deals with the frame of reference for poverty studies. The second part tackles the problem of poverty in Egypt, focusing on its dimensions and how serious it is. The third part handles the analysis of the phenomenon of poverty, its development and its determinants in Egypt during the period that under Study. The fourth part deals with analysing and evaluating the policies and procedures applied to confront the problem of poverty in Egypt. As for the fifth part of the current study, it sheds light on the most important conclusions and recommendations. One of the important results of the study is that the high rates of inflation during this period are due 


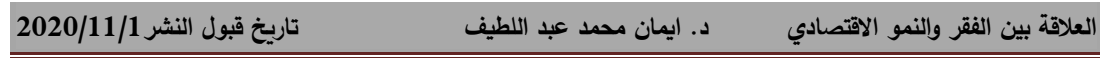

to the implementation of a necessary set of economic reforms, and the low level of education is the factor most closely related to poverty risk in Egypt. The study is concluded with a number of recommendations, including the need to focus on a pattern of inclusive growth that ensures creating more and better job opportunities.

\section{Keywords:}

Poverty - economic growth - extreme poverty - absolute poverty - the roots of poverty - multidimensional poverty -Inflation rateUnemployment-relative poverty- Pro- Poor Growth. 